IJHER International Journal of Humanities and Educational Research ISSN: $2757-5403$

Volume 4, Issue 1, February 2022

\title{
IDEOLOGICAL DIMENSIONS OF INTERACTIVE COMMUNICATION IN DIGITAL ADVERTISING DESIGNS
}

\author{
Huda Fadhil ABBAS 1 \\ Dr, University of Baghdad, Iraq
}

\begin{abstract}
Ideological dimensions are a phenomenon that contributes to raising the level of design that is reflected in acceleration, accuracy and increasing the circulation of advertisements within the digital display of technical media, which has produced new dimensions, cultural, communication, knowledge, and environmental, adding to the participatory communication message a new reality that depends on the features of the new era. In addition, it helped to change the course of design and advertising in line with cases of growth and prosperity. The ideological dimensions were able to reduce the knowledge gap between the advertising message and the diversity of language and cultures of the recipients of the communication message, The advertising designs were characterized by the employment of a design structure that depended on the necessities and requirements Conditions to achieve excellence and effectiveness, pull factors resulting from movement and harmonious variations of visual elements, and activate the symbolic and textual language to promote and show effective communication dimensions. In view of the influences that ideology confers on the design process, the researcher generated the following question: What are the ideological dimensions of interactive communication in digital advertising designs? The aim of the research was based on highlighting the ideological dimensions of interactive communication in digital advertising designs.

As for the second, it included the first topic entitled - Dimensions of Ideology of Interactive Communication - and the second - Ideological Dimensions and Designs for Digital Advertisements, Chapter - And the three factors are effective for the communicative message, those reflections made by those movements in enriching the aesthetic, cognitive and psychological dimension outside the traditional presentation style that characterized each of the samples $(2,3)$. As for the most important conclusions, they included:- The use of information ideology, symbolic culture and discourses of color and shape in the structure of digital advertising design, helped to activate the communicative message in all its cognitive, psychological and social dimensions, because the symbolic message corresponds to the developments of the accelerating digital age, which changed the paths and habits of readings reflected on the recipient.
\end{abstract}

Key words: Ideology, Interactive Communication, Dimension Design, Advertising Design.

http://dx.doi.org/10.47832/2757-5403.12.17

drhudafadihil@comc.uobaghdad.edu.iq, https://orcid.org/0000-0001-5647-5038 


\title{
الأبعاد الايديولوجية للاتصال التفاعلي في تصاميم الأعلانات الرقمية \\ هاى فاضل عباس إس

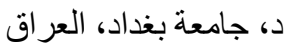

\begin{abstract}
الملخص

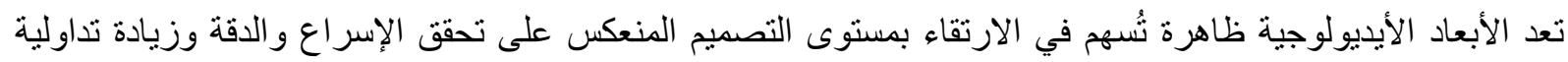

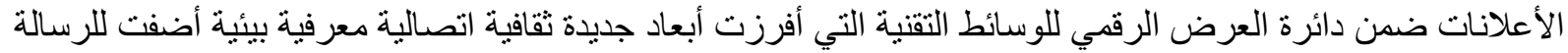

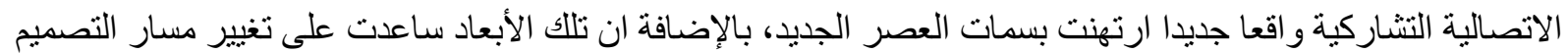

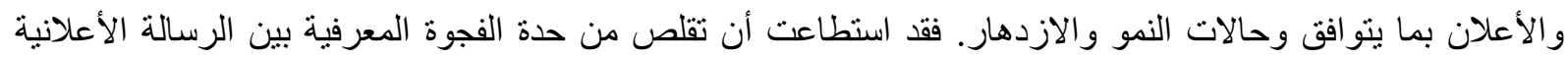

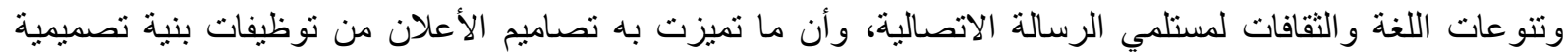

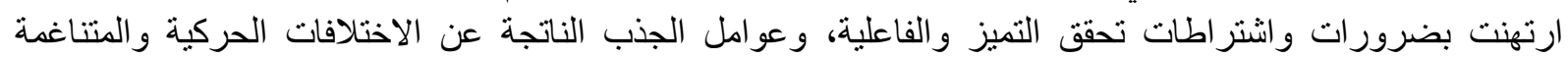

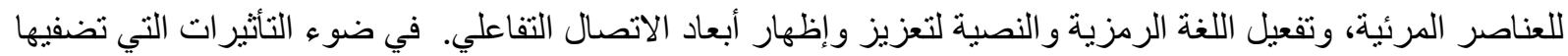

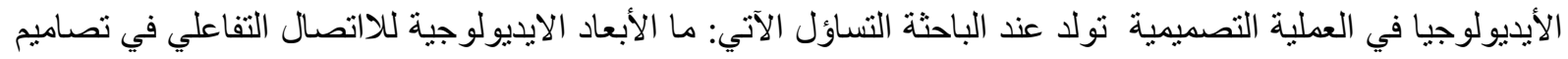
الأعلانات الرقمية ؟ أما هدف البحث ارتكز على ـالكشف عن الأبعاد الايديولوجية للاتصال التفاعلي في تصاميم الأعلانات الرقمية.

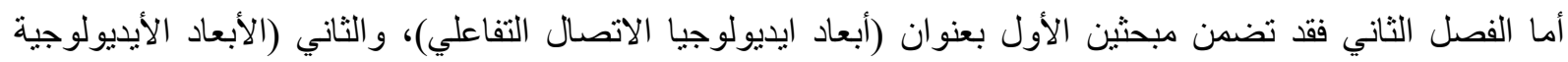

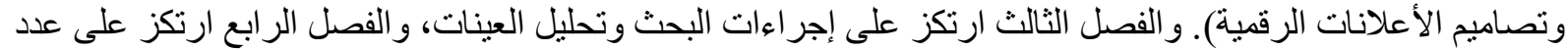

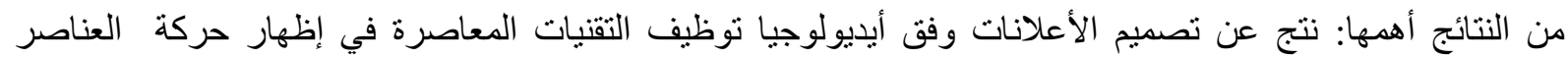

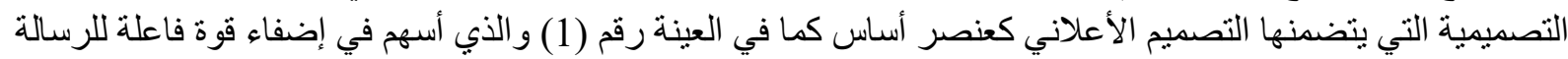

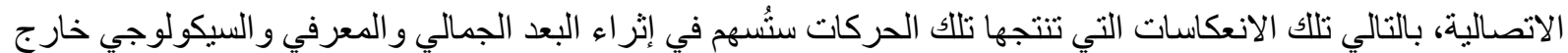

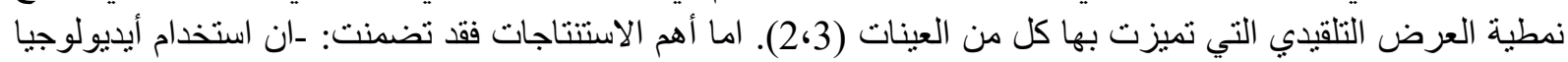

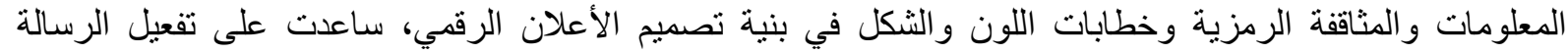

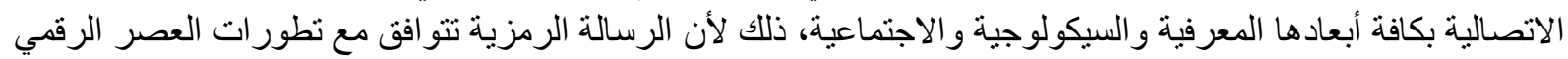

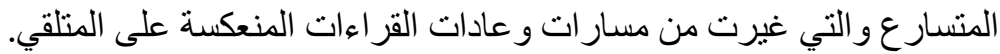
الكلمات المفتاحية: تحليل جغر افي، القوى العاملة التعليمية، التعليم الابتدائي.
\end{abstract}

المقدمة:

الأبعاد الأيديولوجية للاتصال تمثل هيمنة فكرية تحكمها مضامين الرسائل الأعلانية وتقنية التنفيذ، وتلأك الرسائل

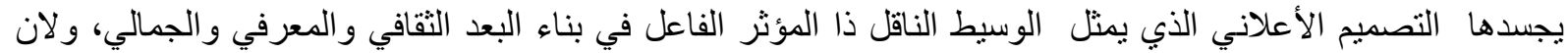

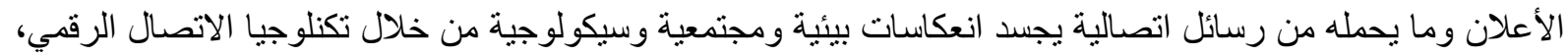

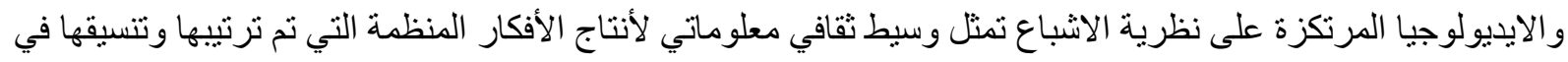

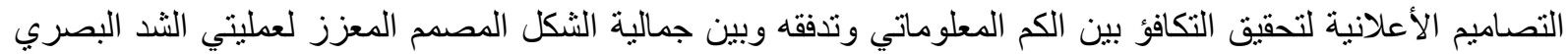
و الجذب لمدركات التلقي، بالتالي ستتحقق الفاعلية الاتصالية. 


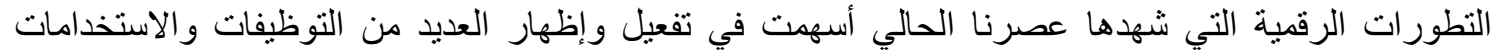

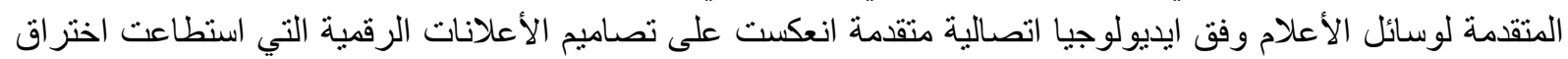

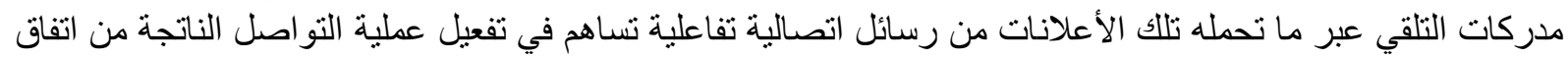
وتحقق امكانية ترجمة الرسالة التي يحملها الأعلان بشكلها المبسط و الواضح و الذي كان للتطور التقني وما أفرزه من

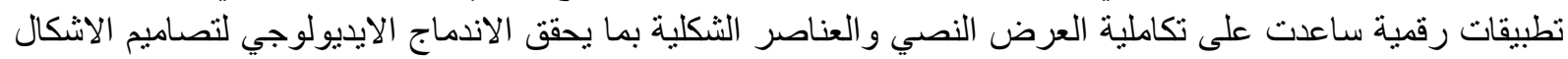

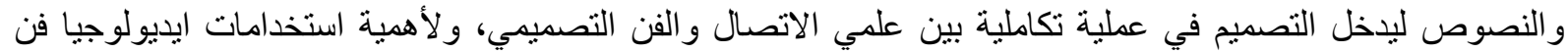

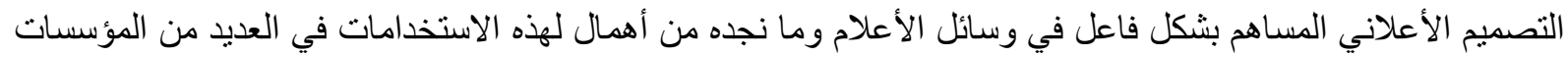

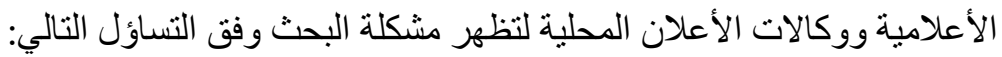

ما الأبعاد الايديولوجية للااتصال التفاعلي في تصاميم الأعلانات الرقمية ؟

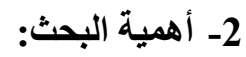

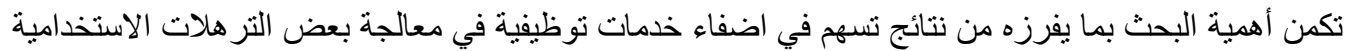

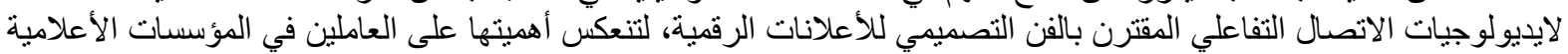

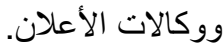

3- - 3دف البحث:

يتحدد هدف البحث في: الكثف عن الأبعاد الايديولوجية للاتصال التفاعلي في تصاميم الأعلانات الرقمية.

4- 2 - حدود البحث موضوعية:

يتحدد البحث في موضو عات الأبعاد الايديولوجية للاتصال التفاعلي في تصاميم الأعلانات الرقمية. زمانية: الفترة

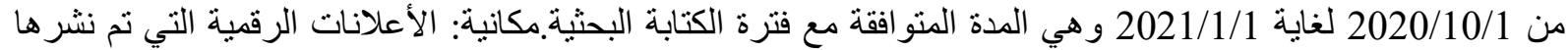
في موقع بينترست 20 " Pinterest "على الثبكة الدولية إنترنت.

5- 5 - 5 مصطحات البحث:

1-الايديولوجيا، التعريف اللغوي: كونها تعود للغة لاتينية لكن البعض قولبها لغولئ لإيا على أنها: ادلوجة، ادلج، إدلاجا ودلّج

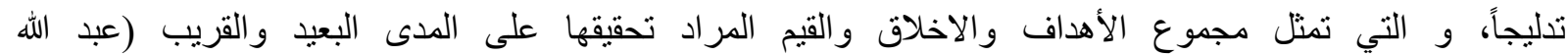

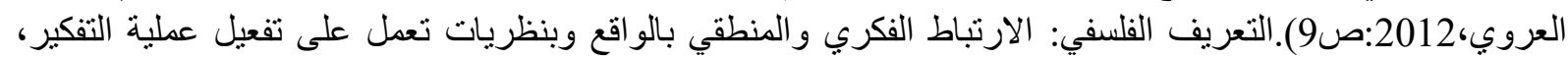

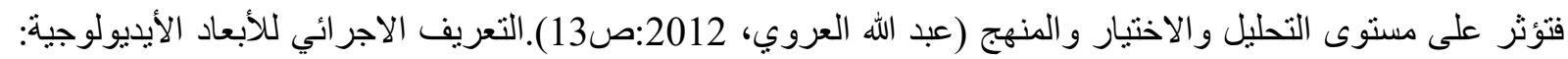

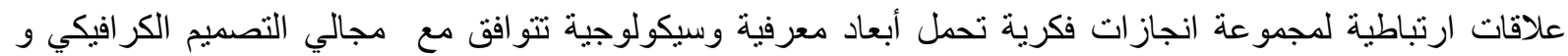

الاتصال التفاعلي.

2-الاتصال التفاعلي: هو اتصال تشاركي ذو اتجاهين مرسل ومستقبل ضمن فترات زمنية تتراوح بين اللاتزامنية

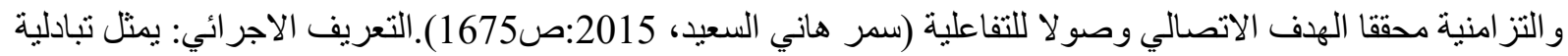

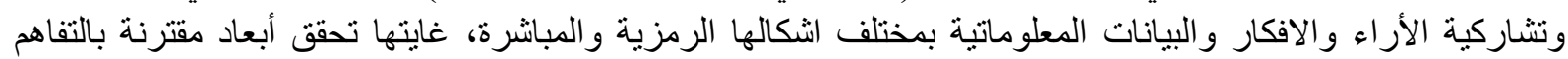
و الاستجابة وفقا للتغذية الر اجعة.

6- منهجية البحث: تم اعتماد المنهج الوصفي (تحليل مضمون) لتو افقه مع منطلبات البحث الحالي.

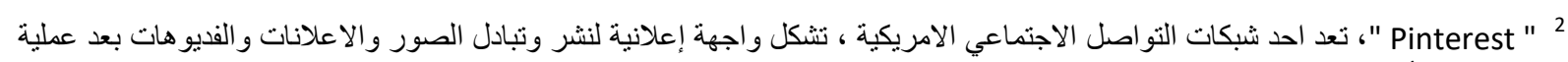

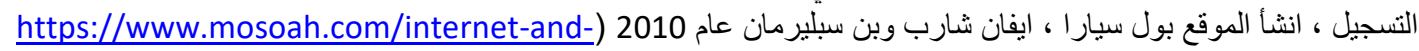

(/telecom/social-network/pinterest

www.ijherjournal.com 
إحدى أهم أسباب تطور الايديولوجيا بشكل عام هو مرورها بعدد كبير من الحقب الزمنية والتاريخية والنظريات

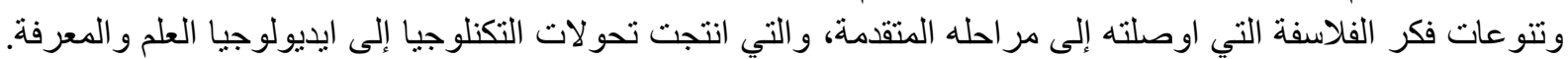

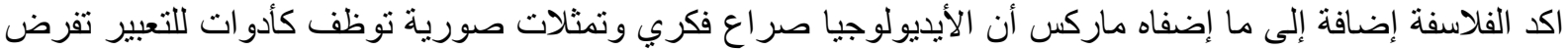

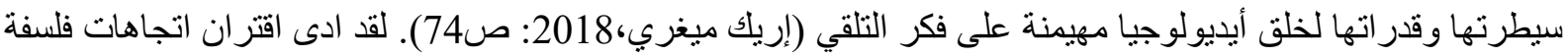

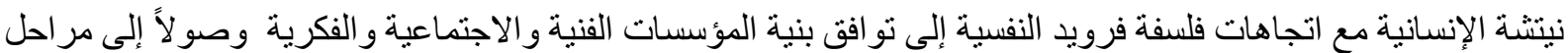

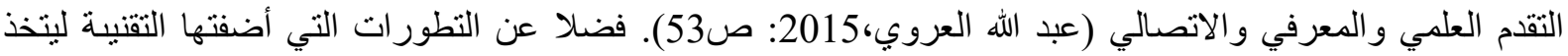

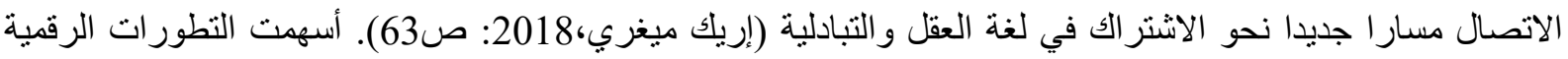

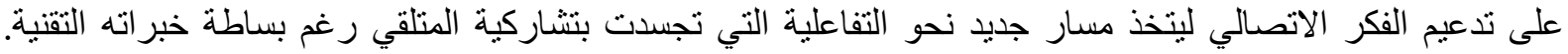

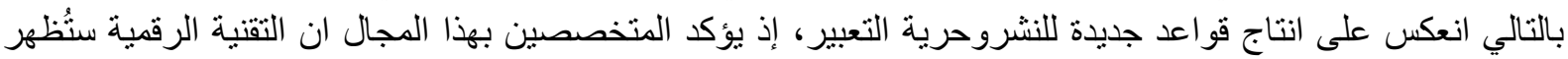

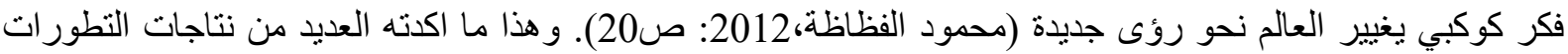

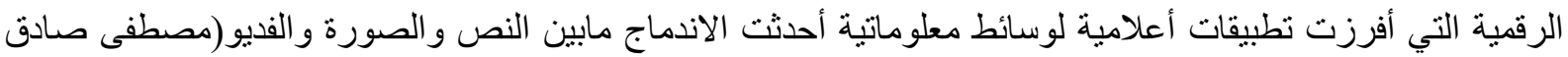

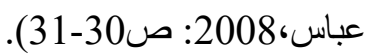

\section{2-1 تحولات ايديولوجيا الاتصال وفق نظرية الاستخدامات والاشباعات:}

نؤكد مع ما تم ذكره اعلاه لابد من ايضاح ان الاتصال قد مر بمسار ات عدة، كما هو معروف وبديهي مبندءا بالمسار

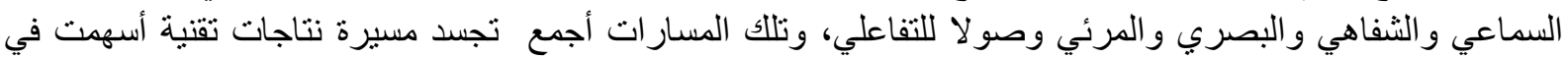
تغيير المسار الاجتماعي والثقافي والايديولوجي وكل جوانب الاحياة ومنها التصميم الكر افيكي. فقد تم توظيف نظريات

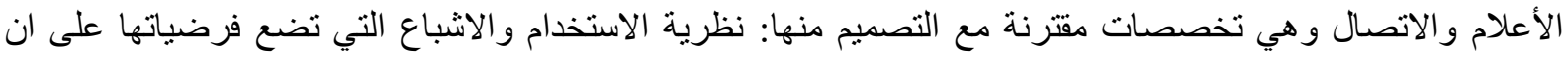

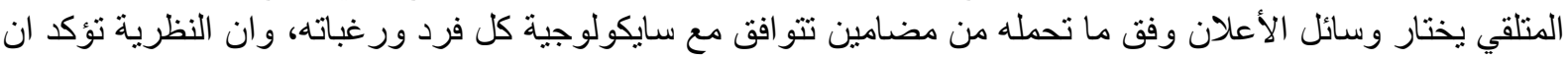

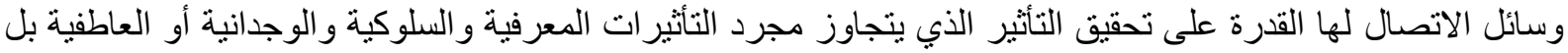

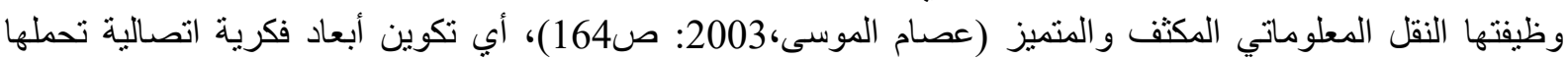

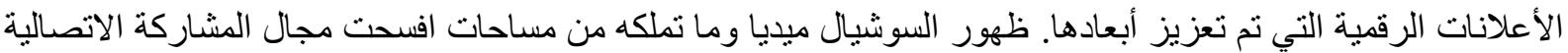

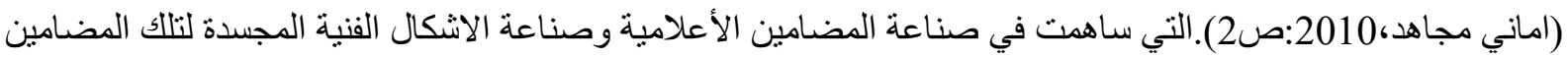

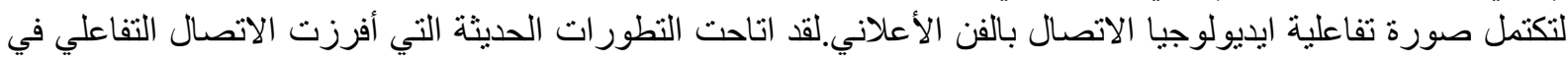

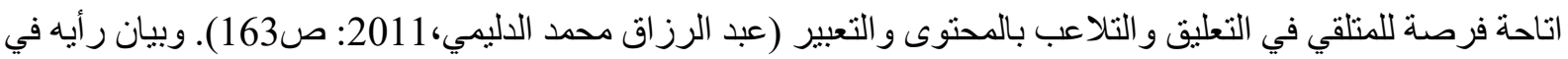

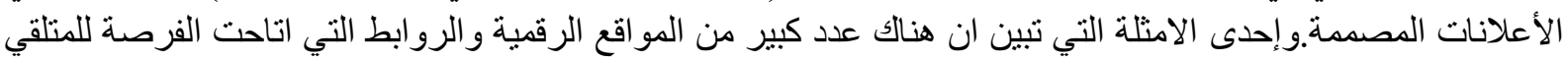

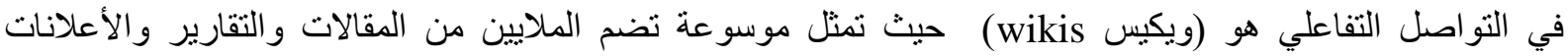

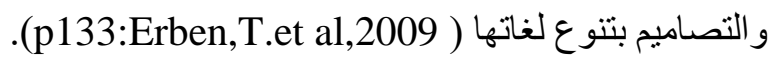

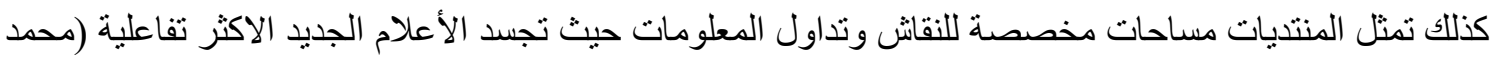

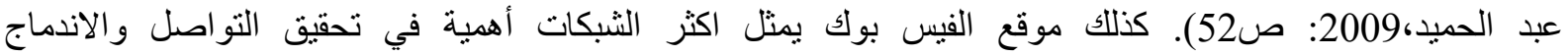

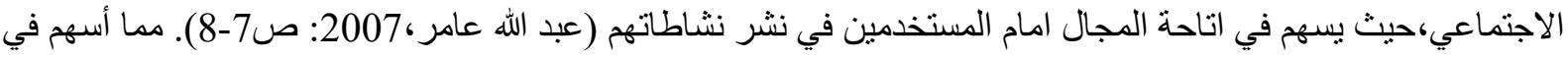

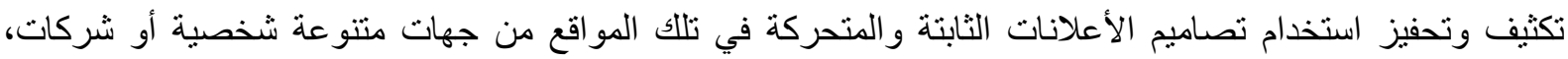

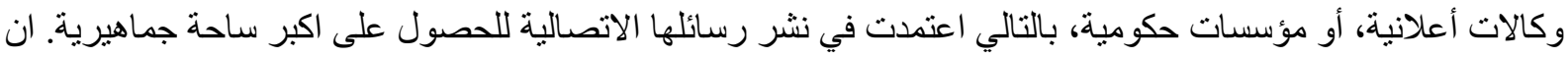

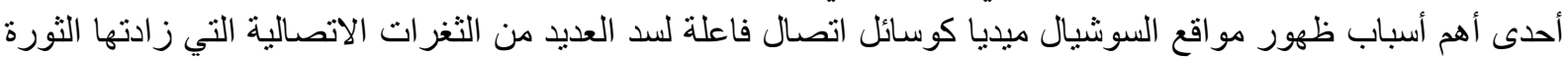

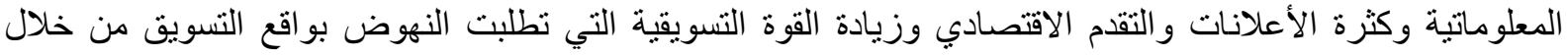

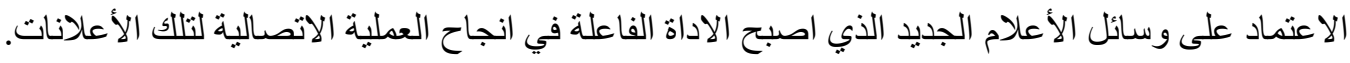
اقتر انات البعد الايديولوجي للاتصال التفاعلي في تصاميم الأعلانات الرقمية:

1- 1أبعاد سيكولوجية:

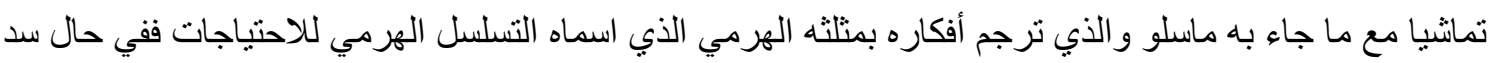

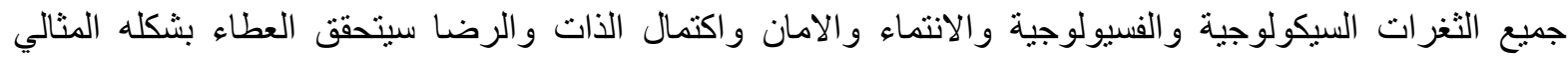


(Aarron Walter,2011:pp5-6)

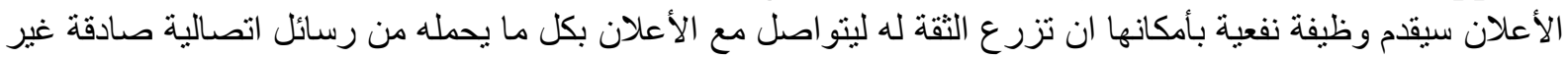

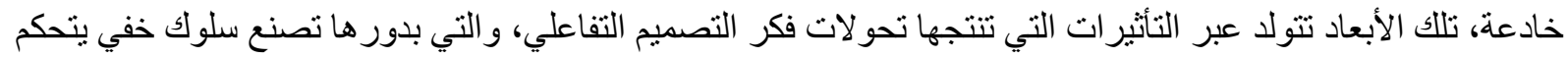

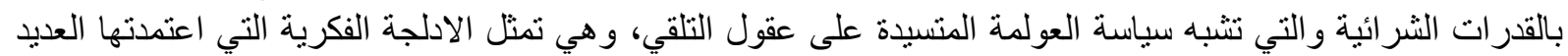

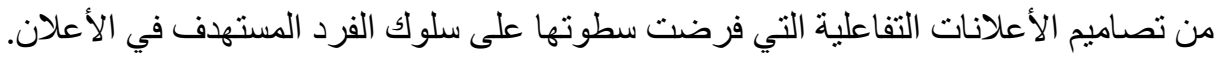

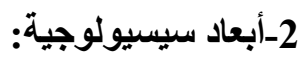

اكد دريكارت ان العقل الإنساني يبحث عن الاستدلال اليقيني لمعرفة الأشياء ذات المضامين التي سبق التعرف

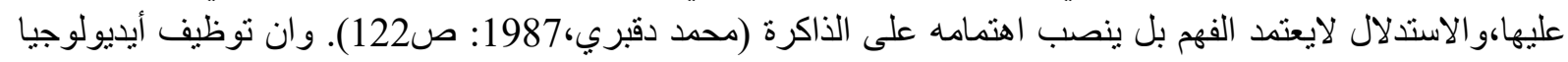

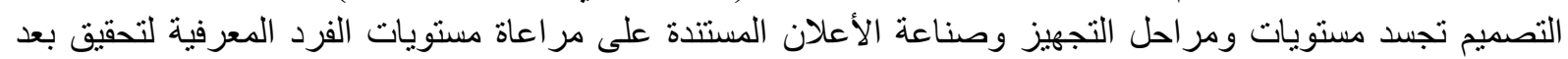

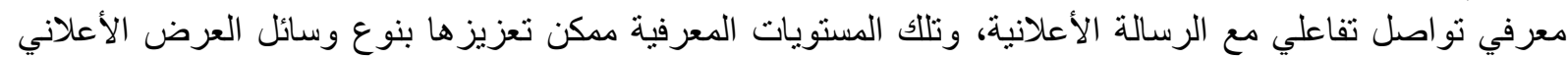

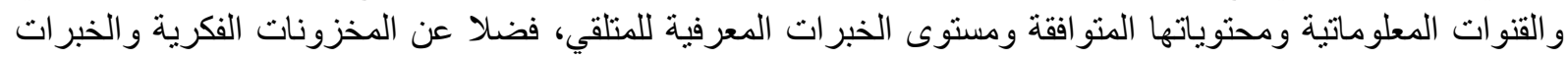

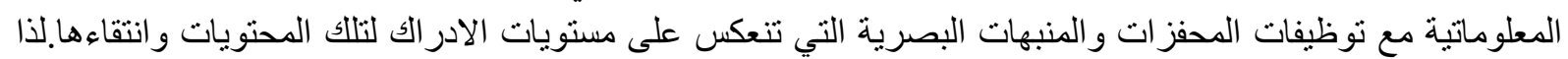

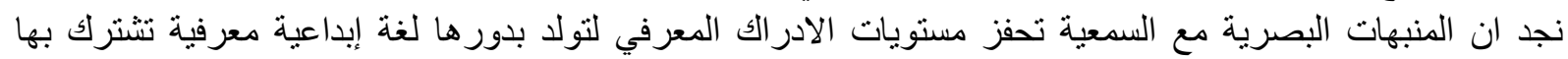

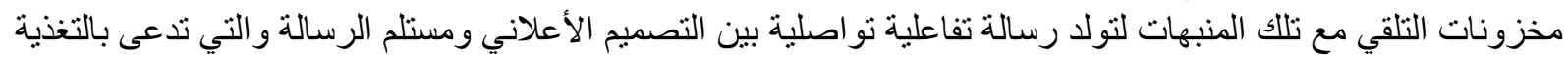

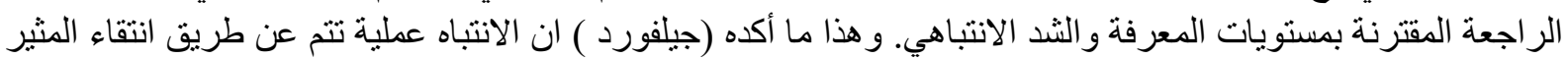

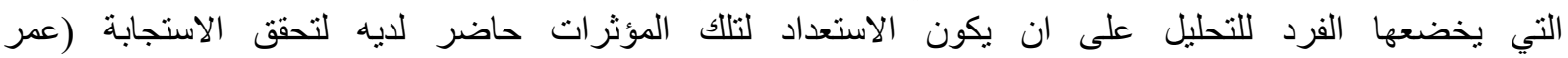

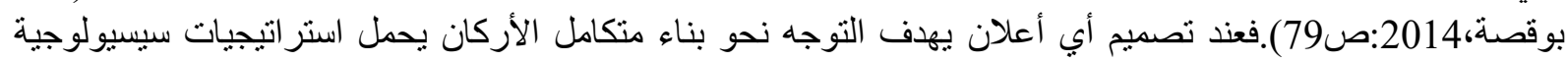

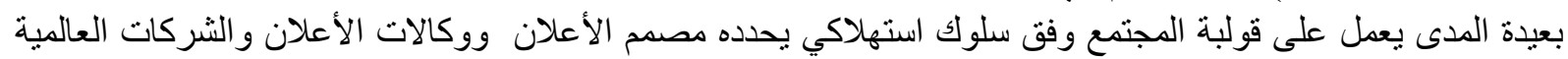

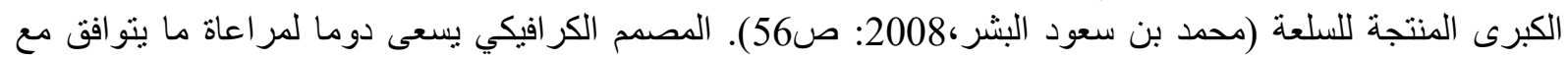

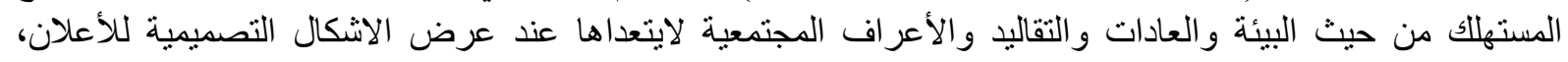

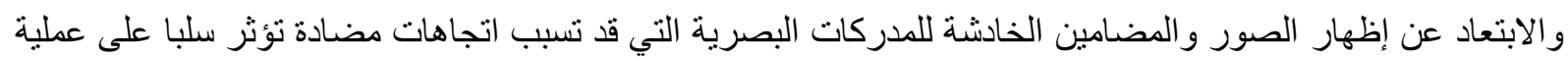
التواصل مع الرسالة الأعلانية بالتالي تتلاشى القيمة الأيديولوجية للأعلان المصدم و الذي يسعى إلى تحقق أهداف التصالية

تقدير الجمال لغة عالمية متفق عليها، يُنظر للجمال على انه حقيقة أساسية ممتعة حسيا لما يحمله من صفات جوهرية معبر عنها ظاهريا (Maggie Macnab,2012:p7). وتصاميم الأعلانات تعتمد الصورة لأنها أحدى أهم أهم العناصر

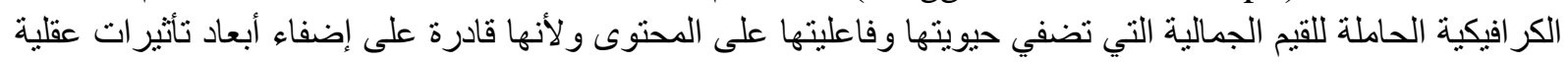

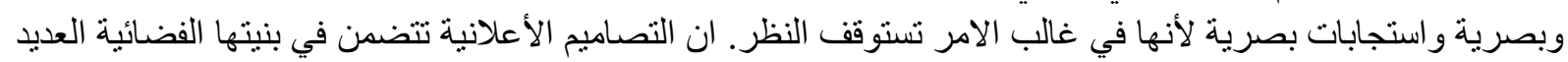

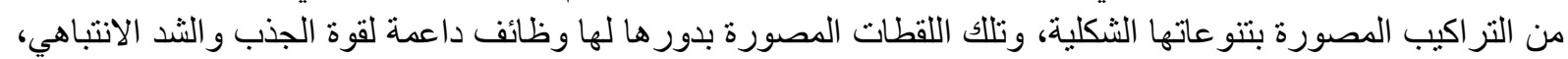

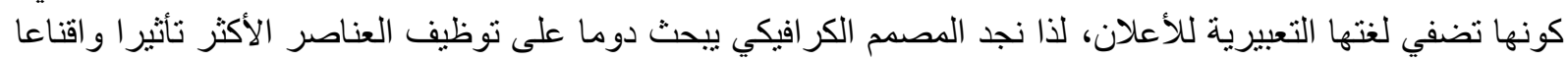

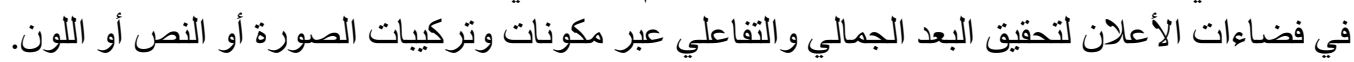

4-أبعاد بيئية:

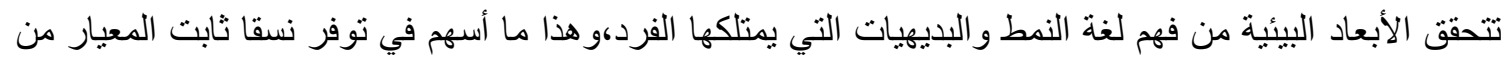

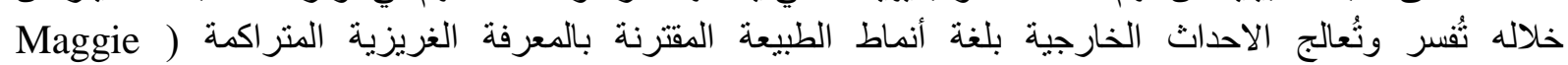

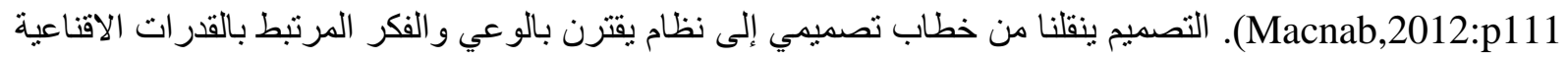

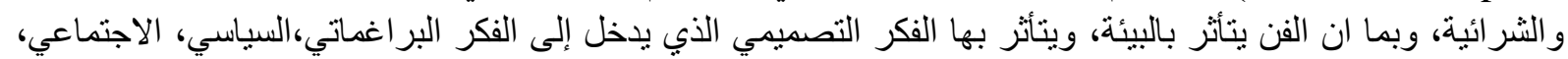

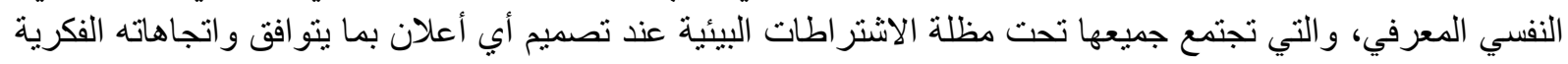

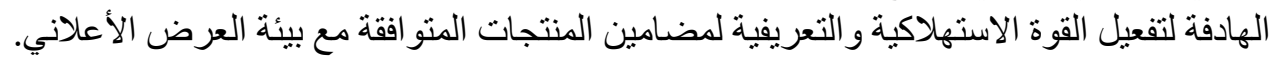

5-بعاد اتصالية تفاعلية:

تحقق القدرة على معرفة مقدار نجاح الحملات الأعلانية التي تسهم في تطوير مسارات استراتيجيات التصاميم

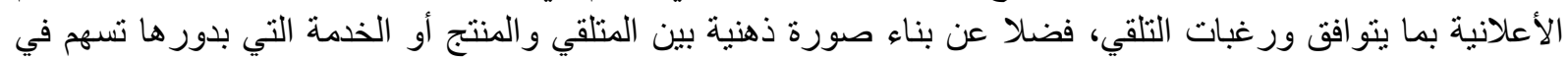

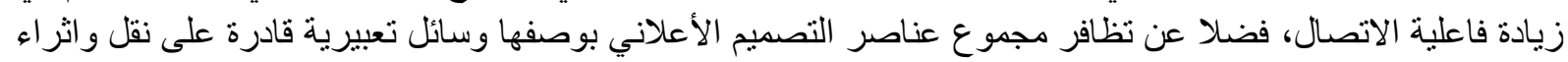


جو انب معرفية وفق أيديولوجيا يتبعها المصمم والتي تسهم في بناء مسار ات نسقية داعمة لقوة الجذب البصري ومدركات

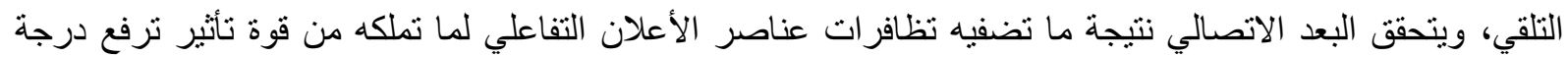

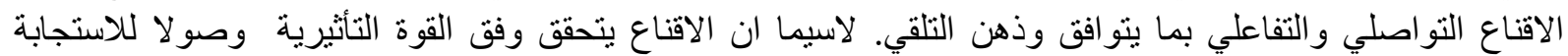

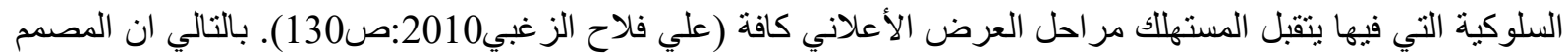

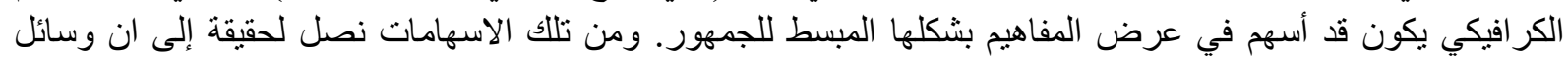

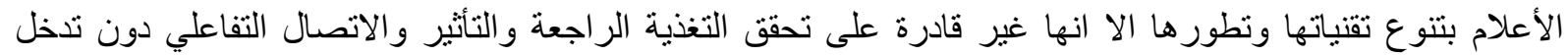

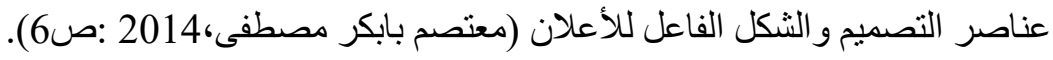

\section{2-2 المبحث الثاني / الأبعاد الأيديولوجية وتصاميم الأعلانات الرقمية} 1-2-2 انعكاسات أبعاد ايديولوجيا الاتصال التفاعلي على تصاميم الأعلانات الرقمية: تأتي الانعكاسات الأتصالية بشكل فاعل على الموجودات زمنها التصميم الأعلاني لاقتر انها بالعلم و المعرفة الذان من التهان

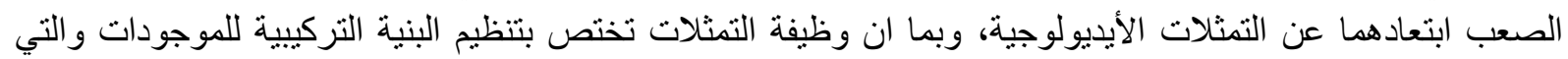

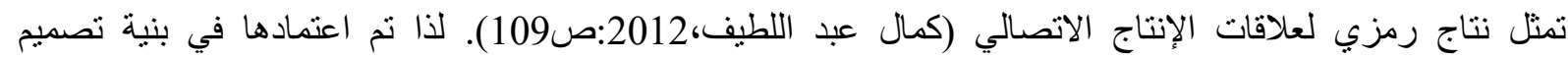

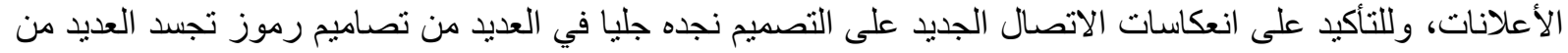

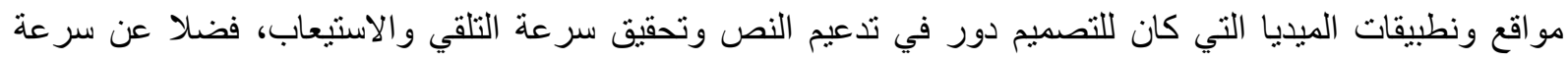

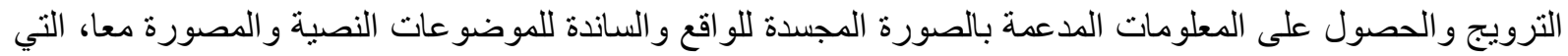

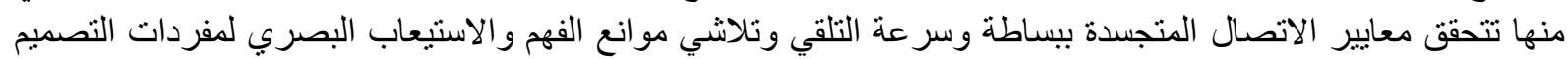

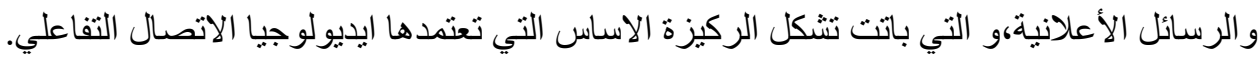

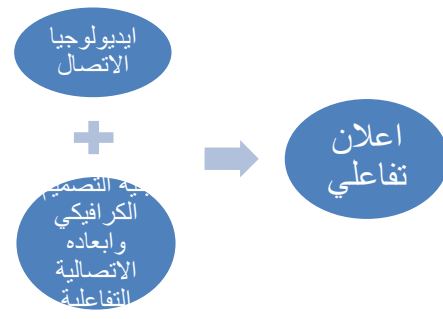

\section{مخطط رقم (1) وضع وتصميم الباحثة يوضح اقترانات الايديولوجيا والتصميم لأتتاج أعلان تفاعلي}

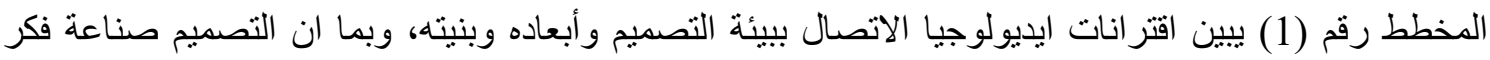
المصمم لذا يعمل التصميم على تنظيم وتغيير سلوك الإنسان الوظيفية والمتعددة الاستخدام، فالمصمم حريص على التئ ايصال

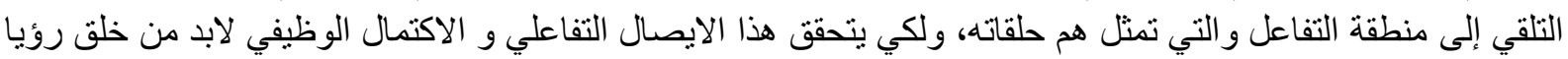

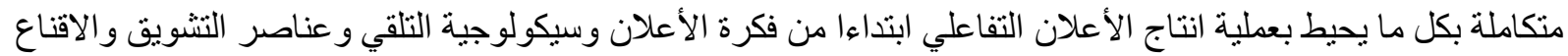

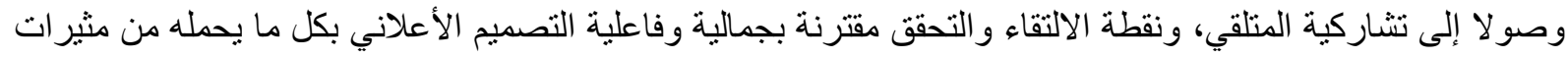

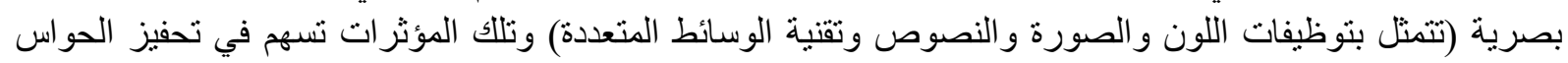

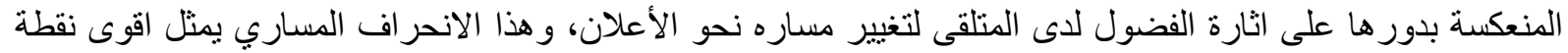

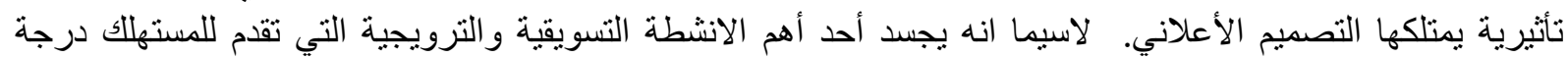

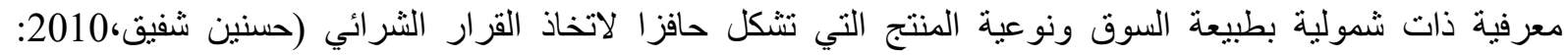

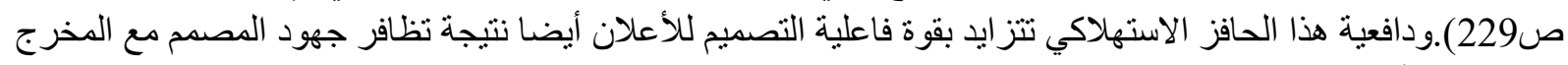

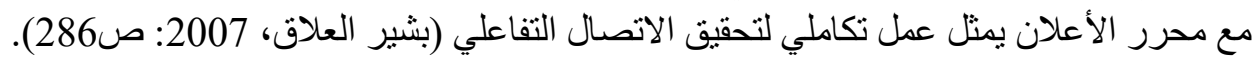
2-2-2 توظيفات المحفزات البصرية لتصاميم الأعلانات الرقمية:

لزيادة فاعلية المحفزات البصرية لابد من معرفة اساس قو اعد التصميم و التنظيم وفق التسلسل المنطقي الذي يحتاج

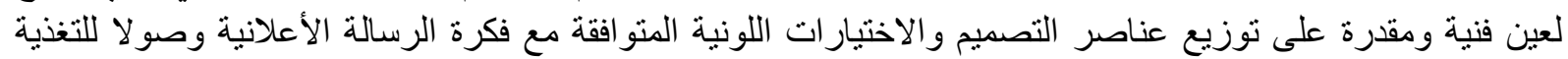
البصرية، وتللك التوظيفات تعتمد على مبادئ عدة أهمها: ترتيب العناصر البنائية للأعلان والتعبير المرئي لترجمة التئة فكرة

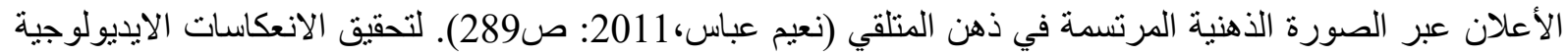

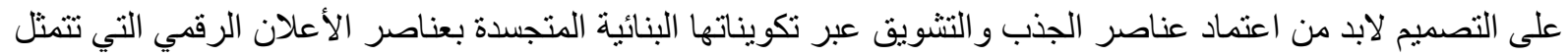




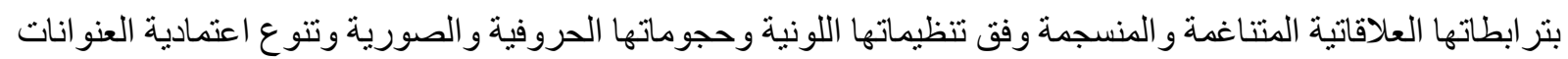

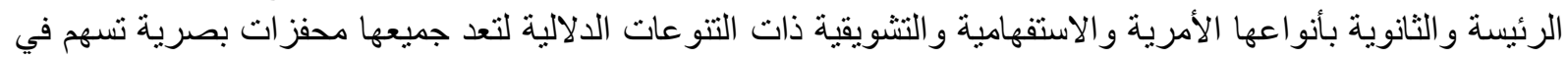

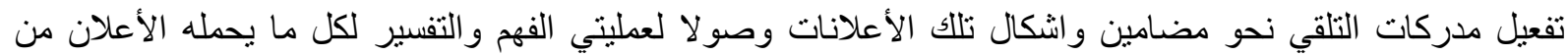

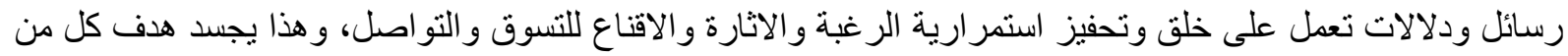
التصميم الأعلاني و العملية الاتصالية.

لذا لابد ان نبين أحدى أهم انواع التر اكيب البنائية المحفزة للأعلانات الرقية: الرقية منها:

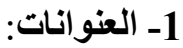

وفق ما اكده الفيلسوف (لوسيان غولدمان) ان العلاقة التراطية بين البنية الاجتماية والاقتصادية من جهة وبين البنية

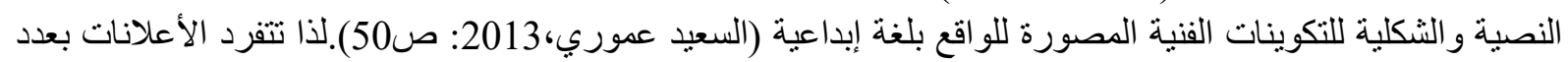

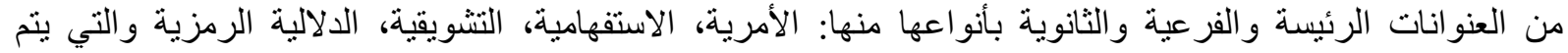

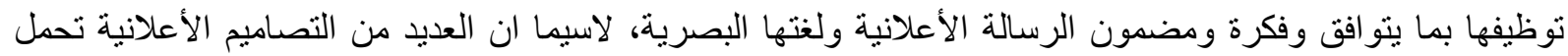

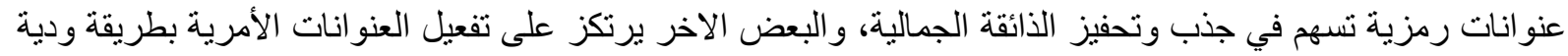

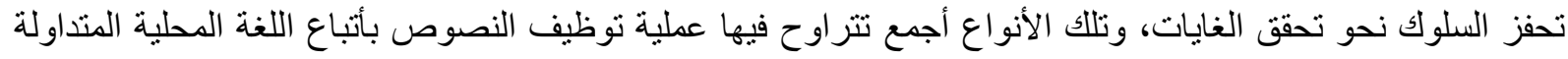

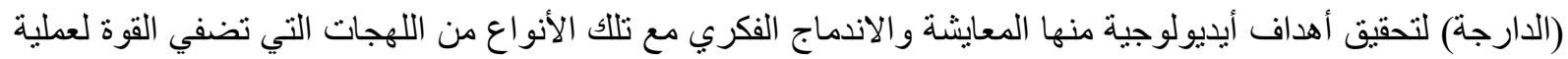

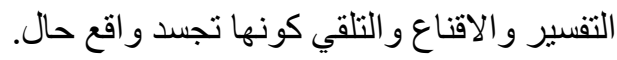

2- الصور (الفوتوغرافية، المرتسمة، الرموز):

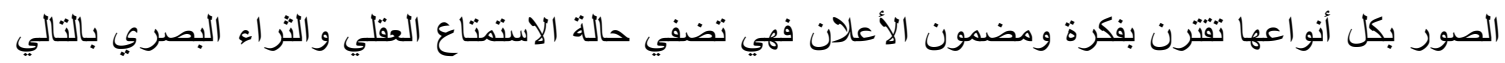

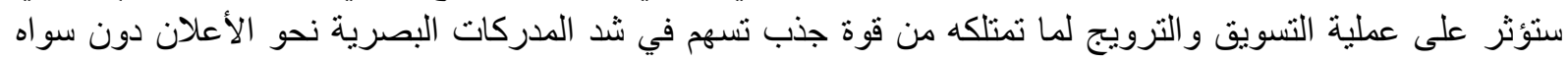

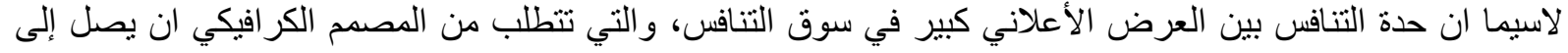

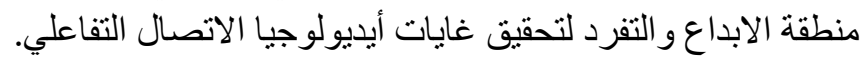

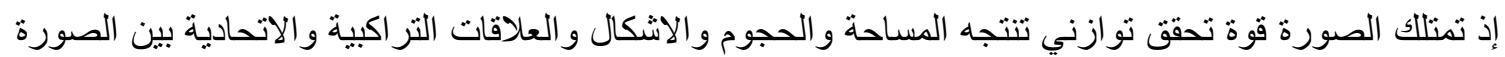

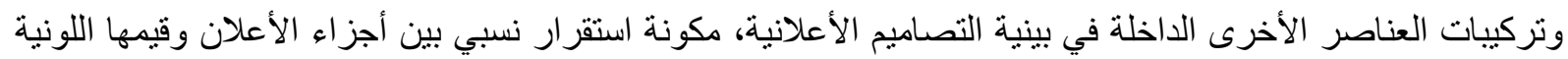

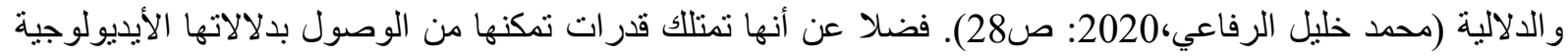

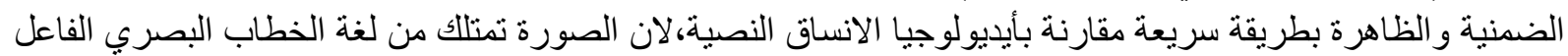

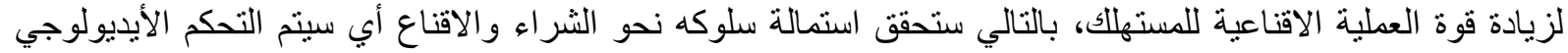

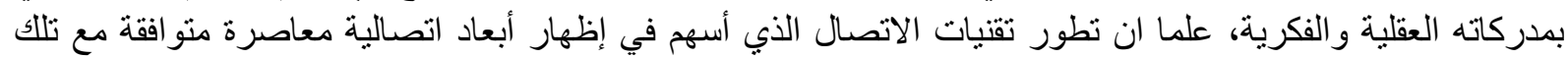

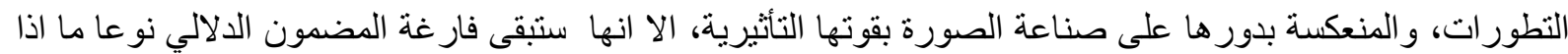

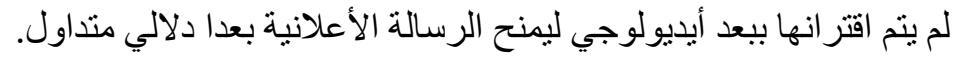

3- الرسالة الأعلانية (النص، الارقام، الروابط):

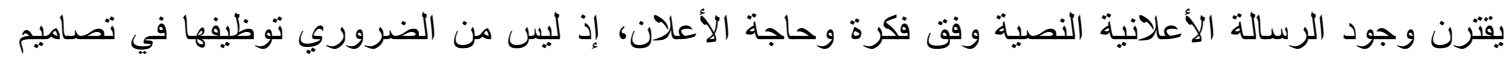

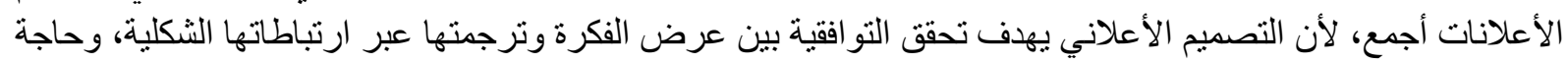

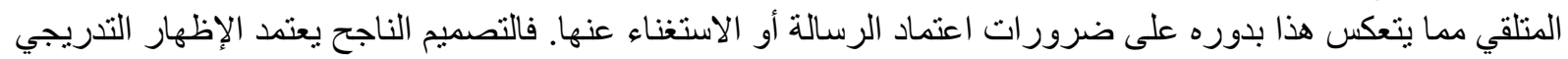

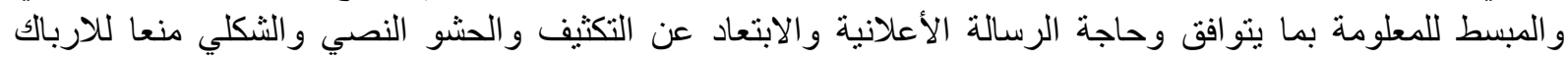

.(Susan M.Weinschenk,2011:p62) 4- الثعار والفضاءات والالوان:

البنية التصميمية للأعلانات تعتمد بشكل كبير على ضرورات الأن ومحددات العرض الابهاري المقترن بالوضوح

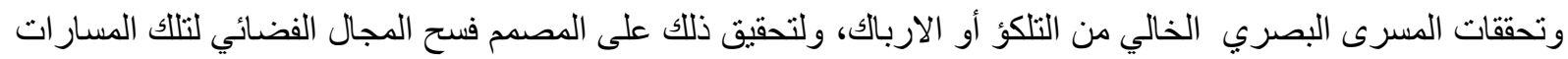
البصرية وتغذيتها بالألوان المتدفقة وما تمنلكه من ايحاءات بصرية توهم عين التلقي بالبعد الر ابع والخامس ليتعايش ذهنيا

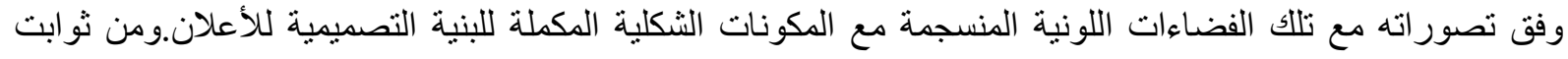

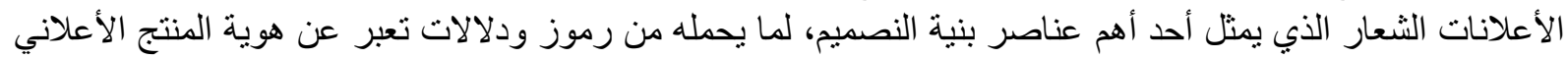

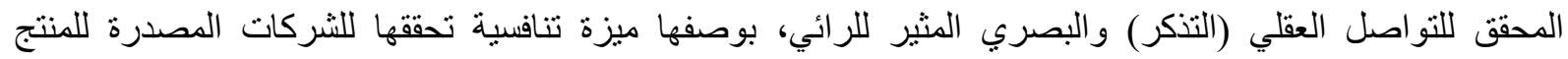

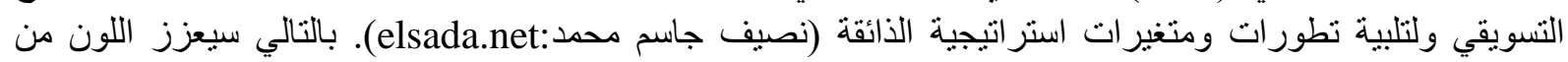


فاعلية الذهن لتحقيق الاقناع وتنشيط الذاكرة مع مراعاة عدم وجود رمزية عالمية للون لتغير مدلو لاتها بما يتبع التنوع

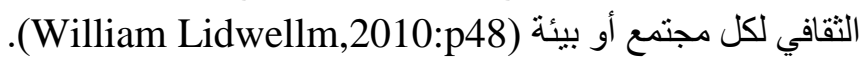

\section{5-أيديولوجيا الإظهار التقني:}

اكدت جوديت وليامسون ان (صناعة الأعلان المعاصر لايهدف إلى تحقيق غايات تعليم الجمهور على كيفية استخدام

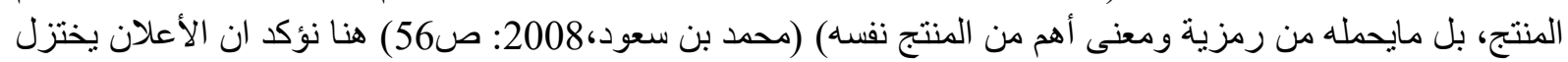

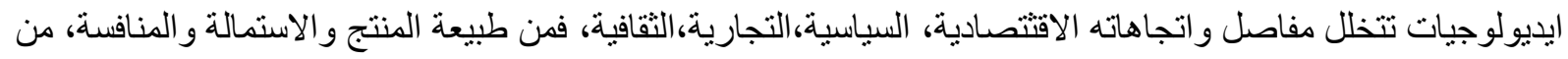

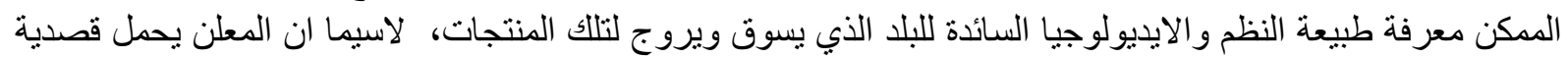

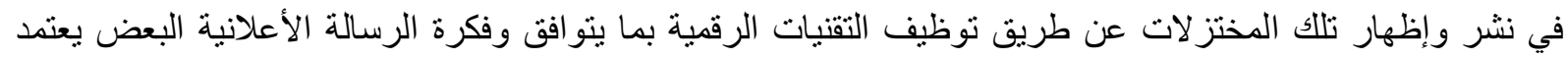

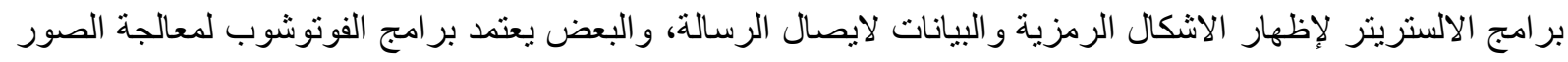

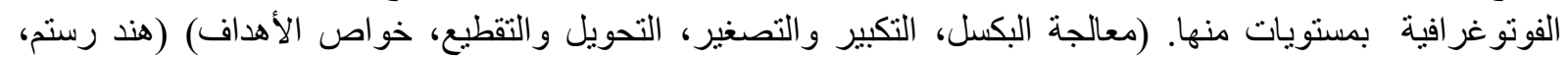

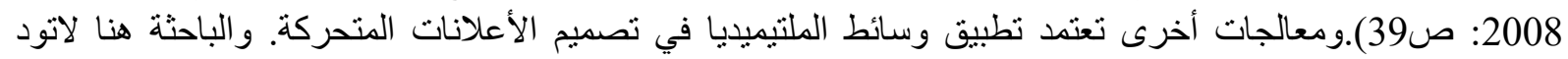

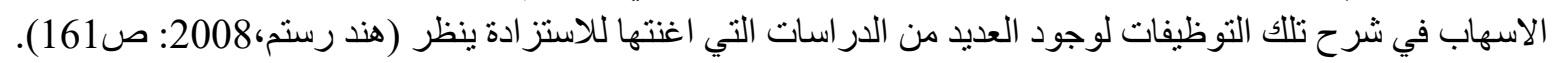


الفصل الثالث ( إجراعات البحث)

1-3 منهجية البحث: اتبعت الباحثة المنهج الوصفي في تحليل النماذج، لرصد الظاهرة وتحليلها بما يقترن وموضوعة البحث المنسجمة مع معطيات الأيديولوجيا وأبعادة البعادها المتو افقة مع بنية تصميم الأعلانات. 2-3 مجتمع البحث: تضمن مجتمع البحث الحالي أعلانات رقمية تم نشر ها على موقع بينترس لتميز هئ ها بالآتي:1ـ اقتران فكرة البناء التصميمي للأعلان الرقمي مع التوظيفات الايديولوجية المعززة لأبعاد اتصالية و أبعاد اخرى.

$$
\text { 2- تنوع موضو عاتها المنو ائمة مع البحث الحالي. }
$$

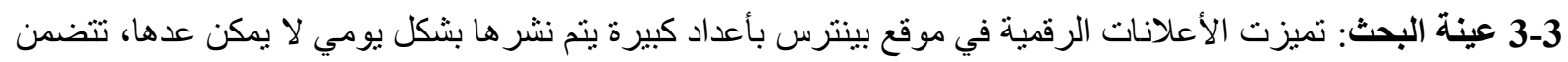

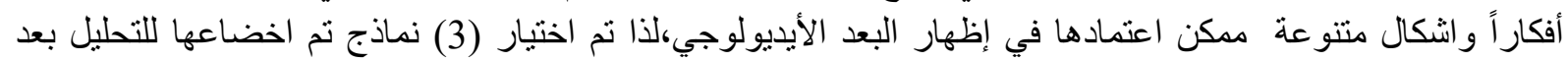
اعتماد الطريقة القصديةه للأسباب التالية: 1.تضفي النماذج المعتمدة وما تحويه من نوظيفات فرصة للباحثة للتعرف على البعد الأيديولوجي للتصاميم الأعلانية من حيث أساليبها وبنيتها التصميمية. 2.تنوع توظيفات البعد الأيديولوجي لتصاميم الأعلانات الرقمية لبيان فاعلية الاتصال. 4-3 أدوات البحث: وصو لا لأهداف البحث تم الاعتماد على ما اسفر عنه الإطار النظري الذبي يجسد خلاصة ادبيات التخصص، لتنكون محاور اعتمدتها الباحثة بوصفها مفاتيح لتحديد الفئات الرئيسة والثانوية لألأداة التحليل (استمارة التحليل) 3. 3-3 طرق جمع المعلومات: اعتمد البحث اثثاء جمع المعلومات على دقة الملاحظة بما ينو افق ودر اسة الظاهرة. 6-3 تحليل العينات: 1-6-3

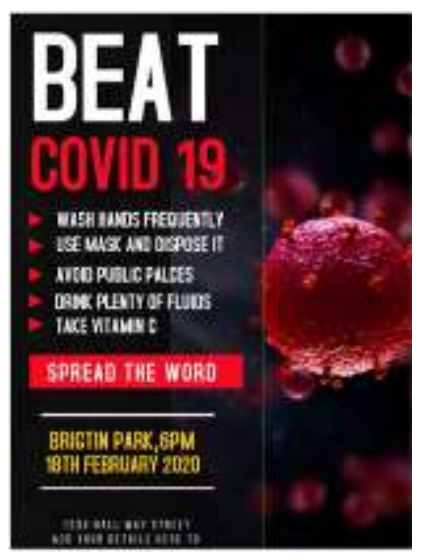

1-أيديولوجيا الإظهار للمثيرات البصرية في تصاميم الأعلانات الرقمية:

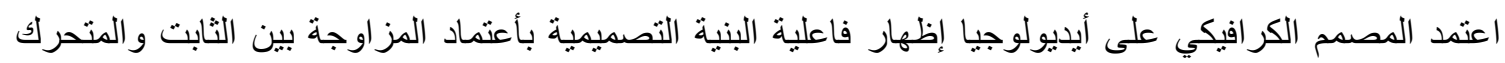

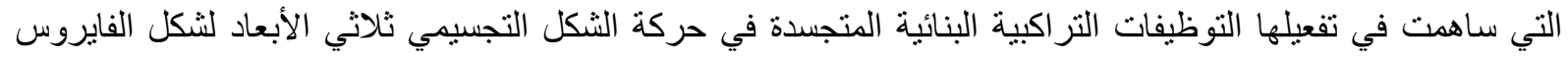

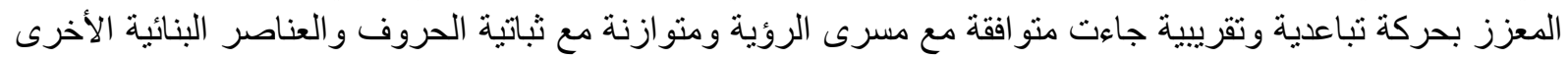

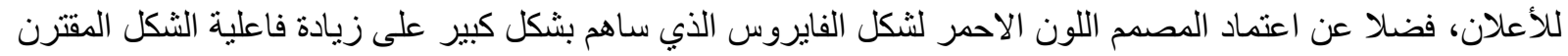

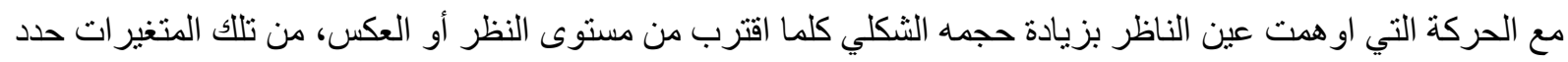

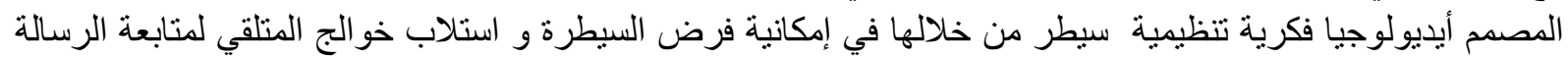

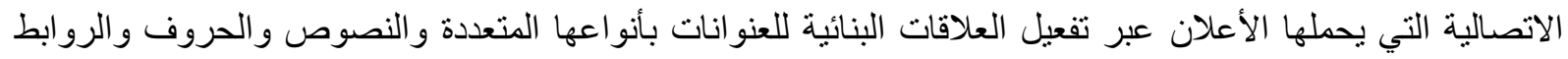

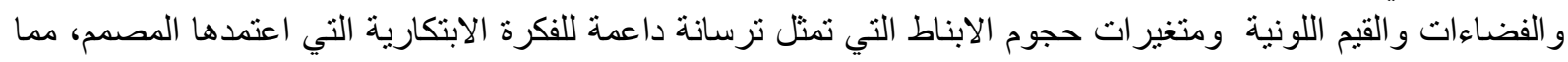

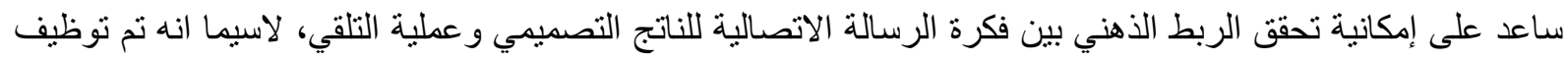

يجري اختيار الوحدات المكونة لهذه العينة بطريقة يؤخذ فيها بنظر الإعتبار ان تكون قريبة من المتوسط للظاهرة التي يجري قياسها أو بحثها. 3 
العنو انات بأحجام ابناط متنو عة وبأنو اع متعددة فقد استطاع المصمم المز اوجة بينهما لتحقيق الدعم الاتصالي معتمدا العنوان

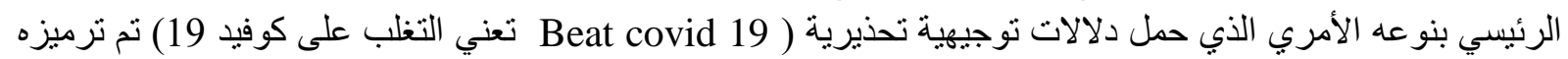

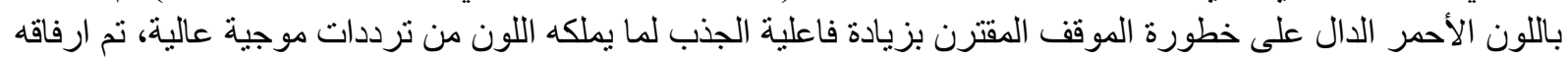

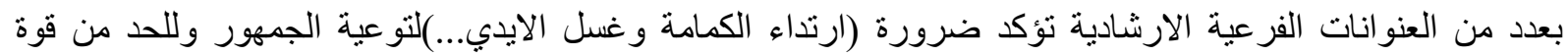

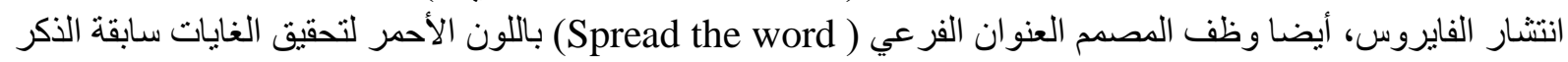

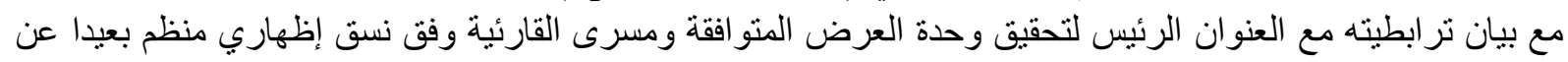

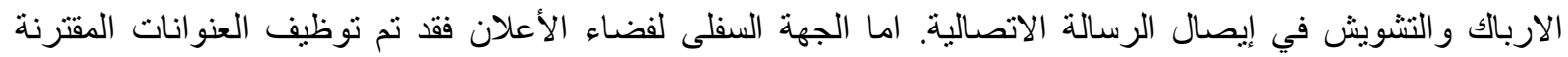

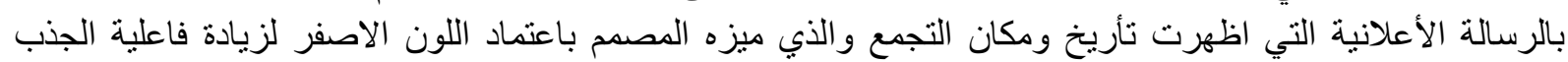

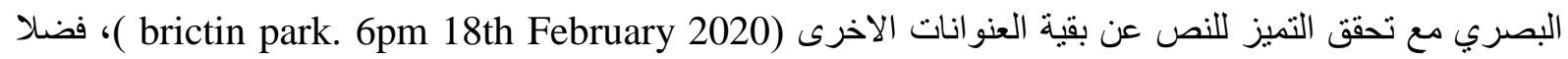
عن اعتماد عنوان اخر باللون الابيض استكمالا للرسالة الأعلانية لتحقيق التواصل مع الجمهور المتلقي ( 1234 ) .HALL WAY STREET. ADD YOUR DETAILS HERE TO 2- انعكاسات الأبعاد الأيديولوجية على تصاميم الأعلانات الرقمية:

تجسدت الأبعاد الأيديولوجية في تصمييم الأعلان الرقمي الناتج من التنوعات اللونية المقترنة بمؤثرات سيكولوجية

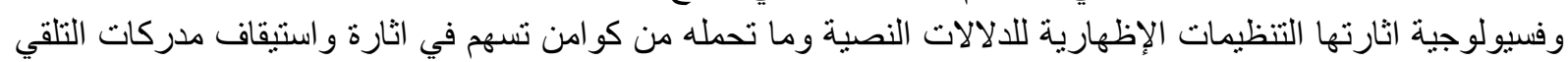

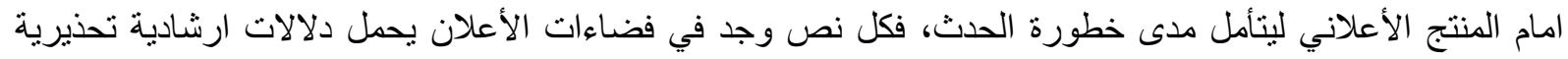

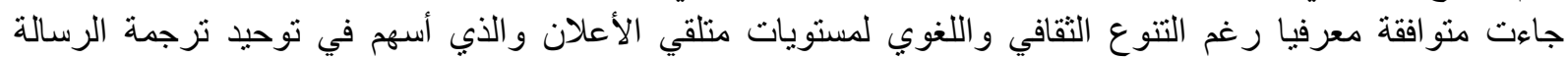

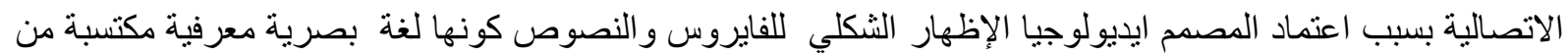

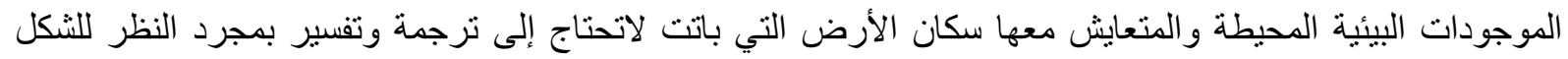

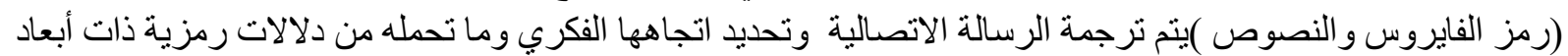
بيئية وجمالية مثيرة للمحفز ات البصرية.

\section{3-تحولات أيديولوجيا الاتصال التفاعلي وفق نظرية الاستخدام والاشباع المنعكسة على تصاميم الأعلانات الرقمية:}

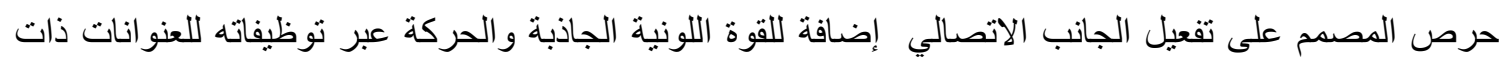

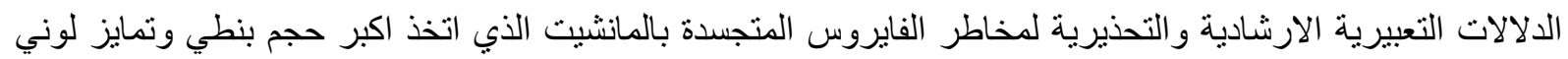

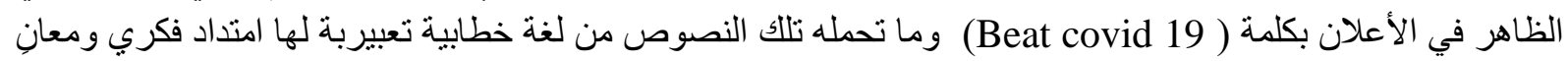

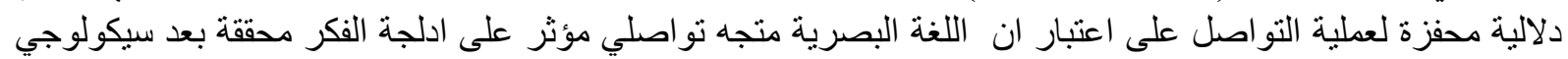

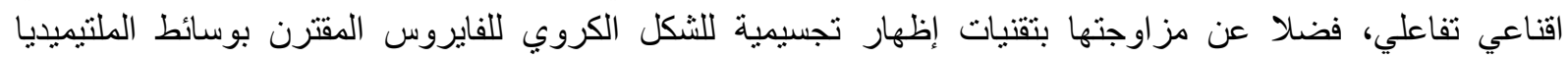
بأعتماد وسيط فديوي مجسد لحركة شكل الفايروس، ومن جميع تللك التوظيفات التقنية نم تفعيل العملية الاتصالية التي تؤكدها نظرية الاستخدام و الاشباع من حيث التكثيف المعلوماتي المقترن برو ابط تشعبية ظهرت التهر في الأعلان

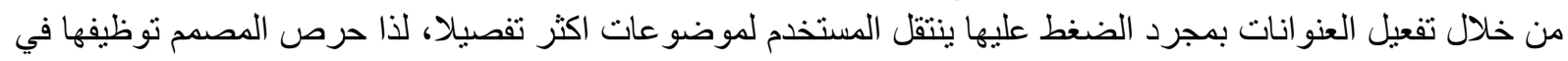

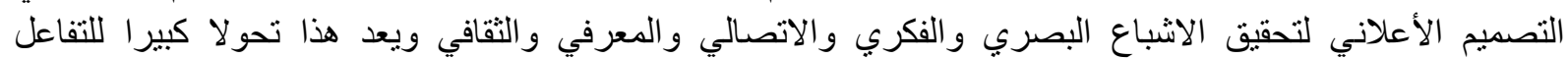

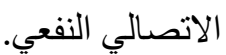




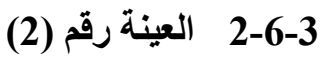

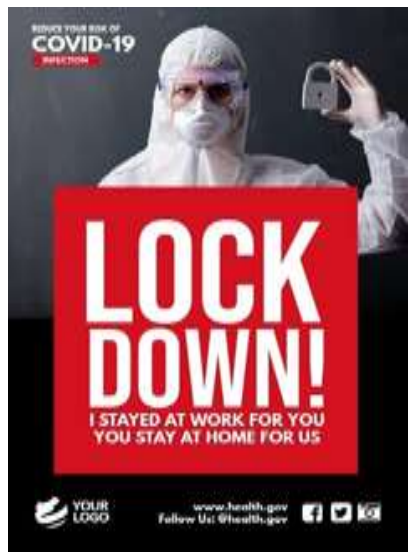

1-أيديولوجيا الإظهار للمثيرات البصرية في تصاميم الأعلانات الرقمية:

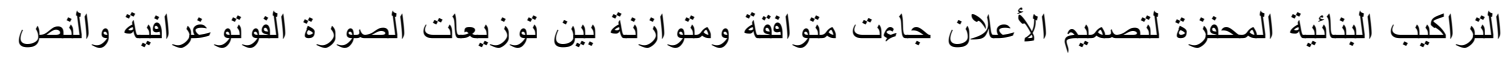

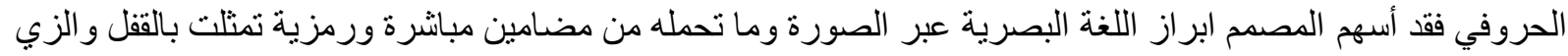

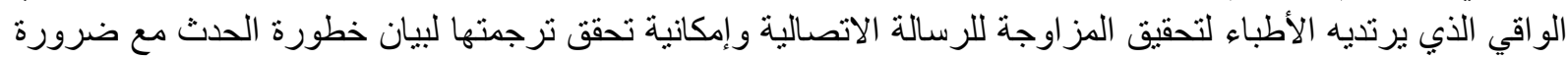

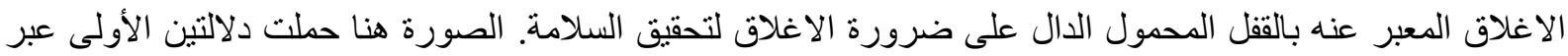

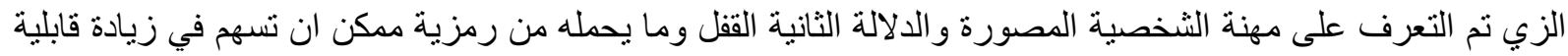

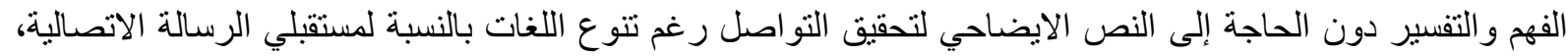

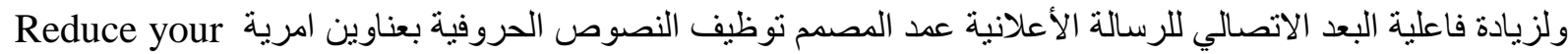

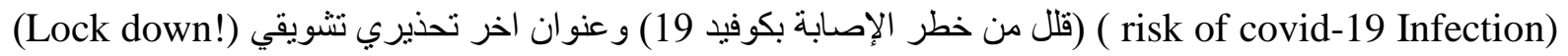

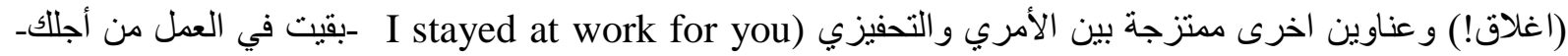

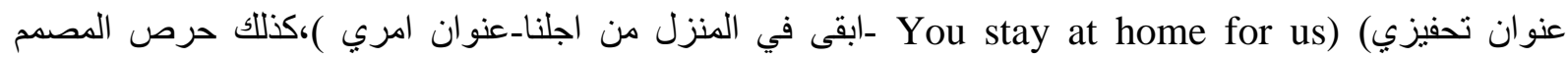

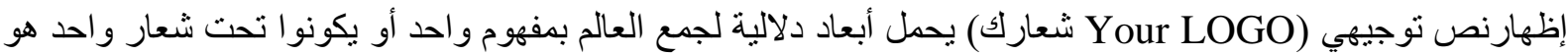

ومن العناصر التصميمية التي استطاع المصمم توظيفها وفق نركيبات بنائية أسهمت بزيادة فاعلية الرسالة الاتصالية

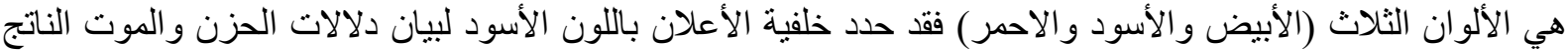

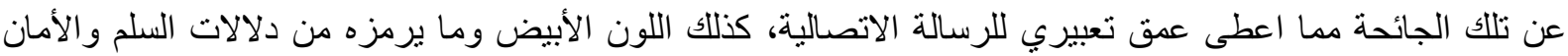

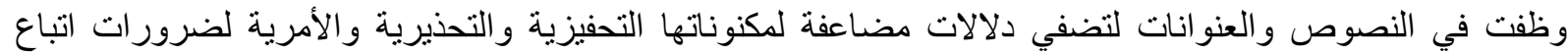

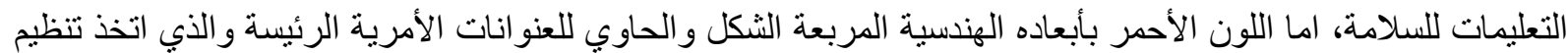

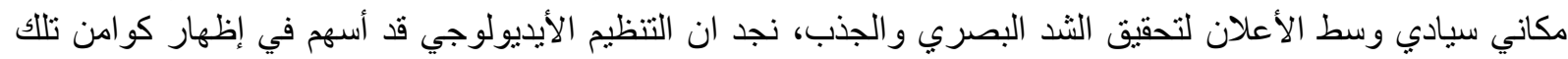
العنوانات بفاعلية عالية، بالتالي ان تلك التوظيفات التعبيرية قد زادت من فاعلية التكثيف الإظهاري لدانلاتلات كل منها

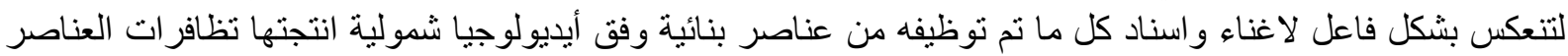

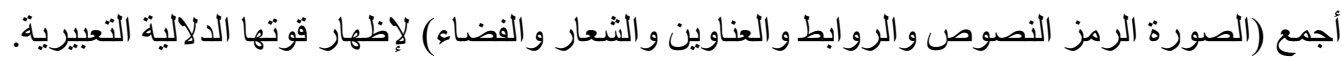
2- انعكاسات الأبعاد الأيديولوجية على تصاميم الأعلانات الرقمية:

تضمن التصميم الأعلاني أبعاد متعددة استطاع المصمم ان يزيد فاعليتها عن طريق تتظيماته البنائية المترابطة

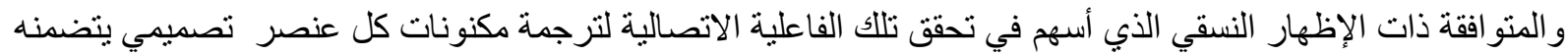

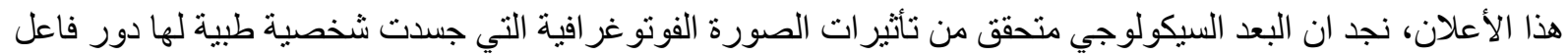
في زمن الجائحة وما قدمه الصف الأول من جهود فاعلة لتتعكس على ضرور التيكات التعاطف و التأثر بمجرد تحقق المدركات

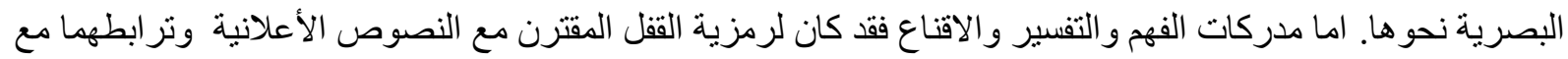

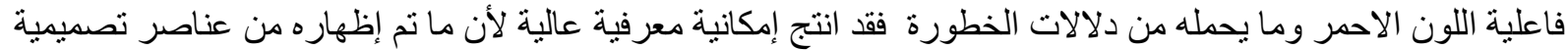

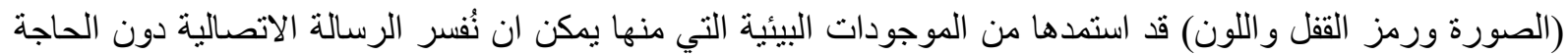

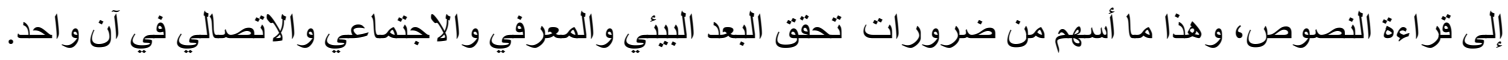


3-تحولات أيديولوجيا الاتصال التفاعلي وفق نظرية الاستخدام والاشباع المنعكسة على تصاميم الأعلانات الرقمية:

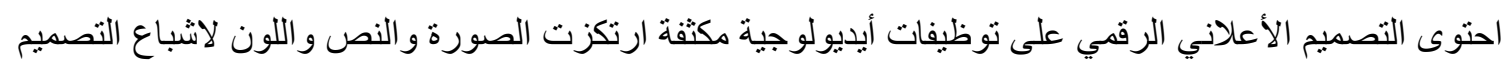

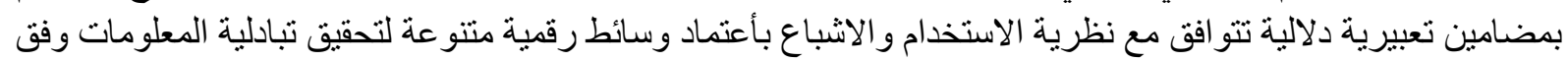

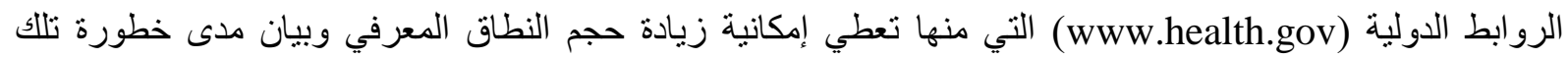

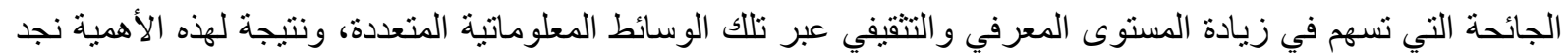

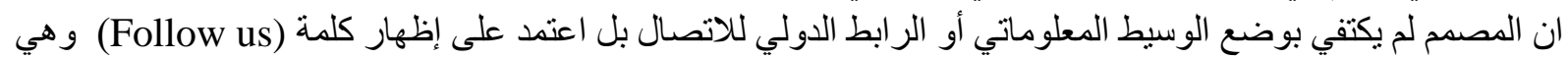

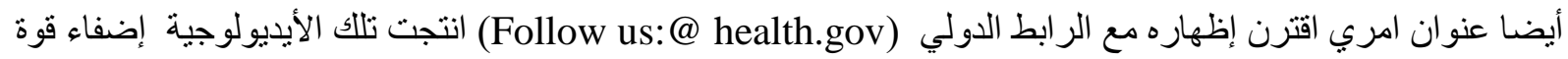
و إمكانية زيادة فاعلية التو اصل و الاستمر ارية في استقبال الرسالة الاتصالية.

3-6-3

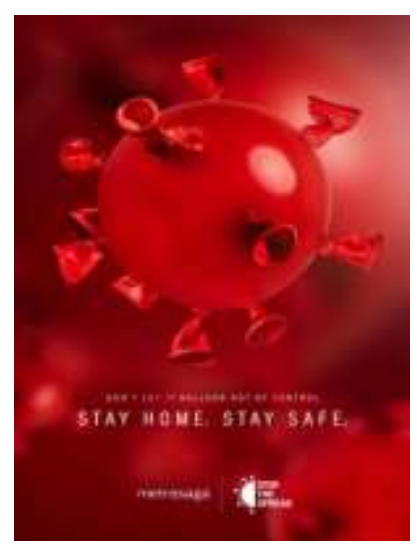

1-أيديولوجيا الإظهار للمثيرات البصرية في تصاميم الأعلانات الرقمية:

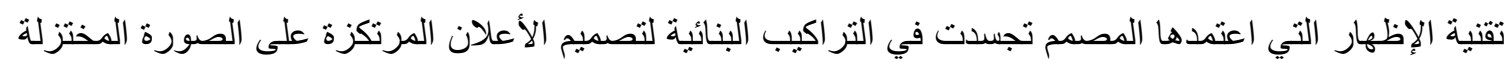

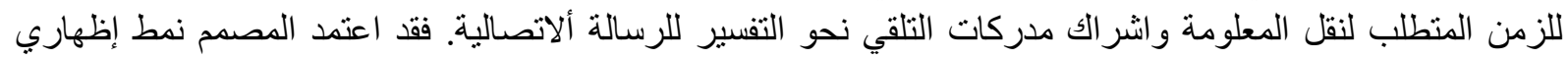

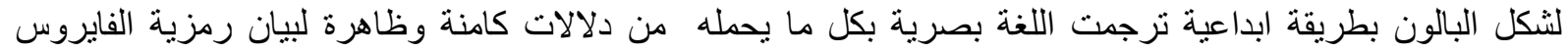

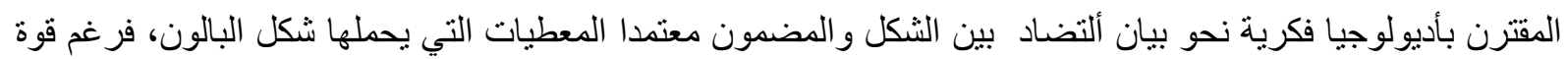

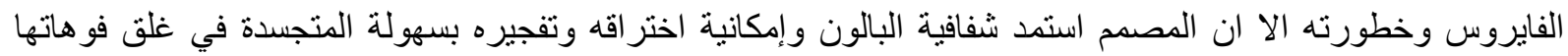

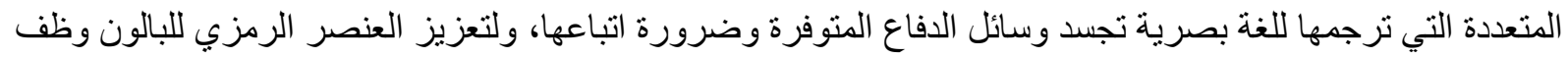

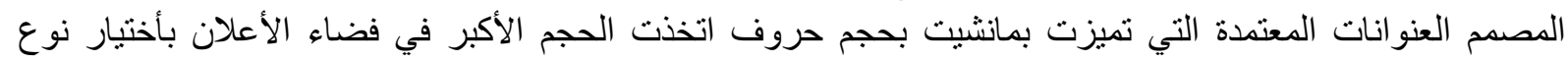

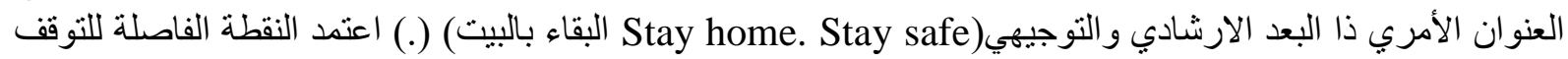

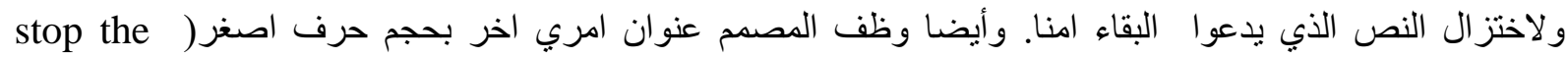

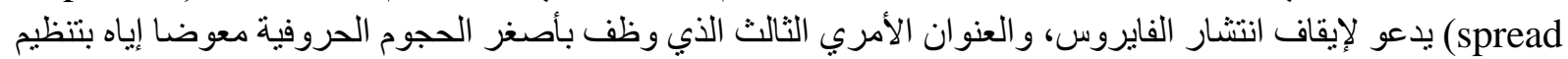

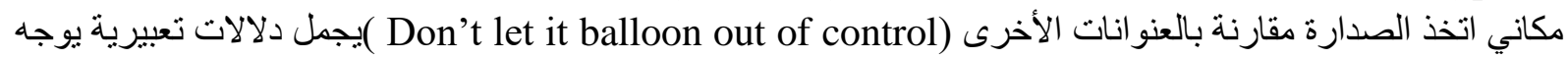

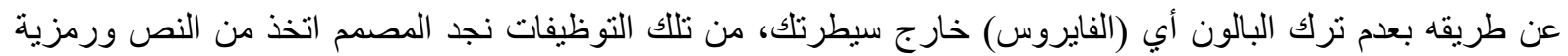
الثكل ودمجهما بتوليفة بصرية تحمل مضاكئ بالين غير ظاهرة.

2-انعكاسات الأبعاد الأيديولوجية على تصاميم الأعلانات الرقمية:

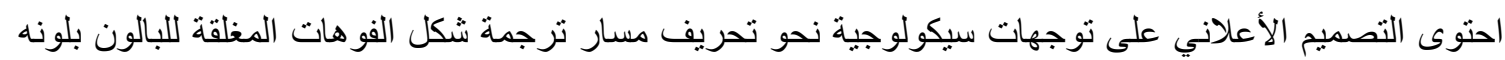

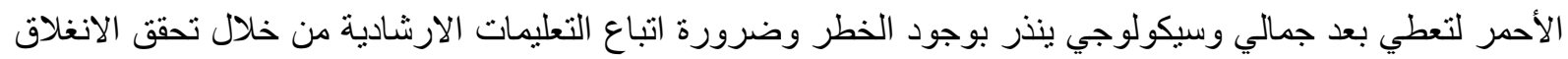

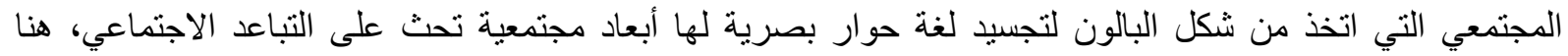

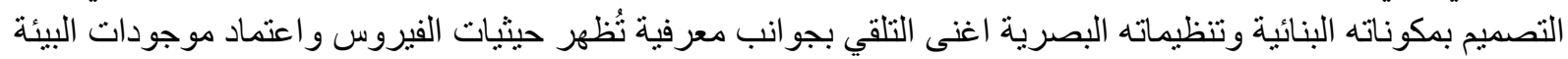
لتجسيد تلك الرسائل وفق أيديولوجيا فكرية أسهمت في تحقيق الأبعاد أجمع غاياته تحفيز الحث التئن التقافي. 3-تحولات أيديولوجيا الاتصال التفاعلي وفق نظرية الاستخدام والاثباع المنعكسة على تصاميم الأعلانات الرقمية:

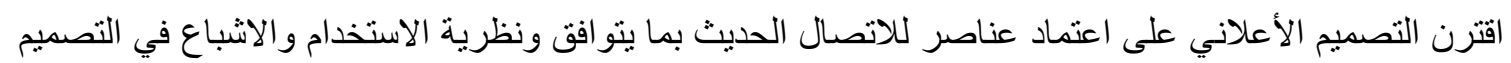

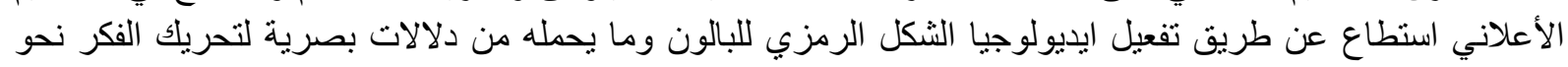


المضمون لتحقيق الاتصال الفاعل و الاقناع مع الرسائل الأعلانية التي يحويها الأعلان بكل تفصيلاته، هنا حرص المصات التصم

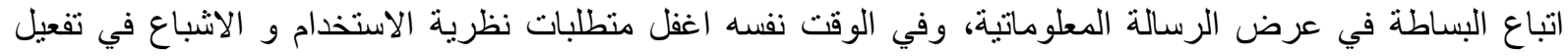

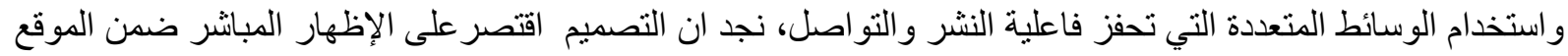

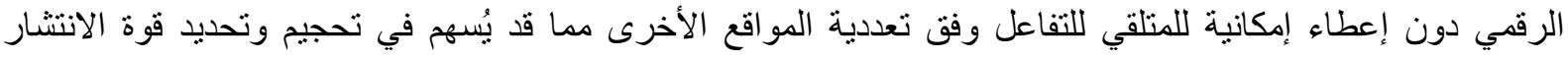

التفاعلي. 
1-نتج عن توظيف تركيبات العناصر التصميمية وفق أيديولوجيا معلوماتية منظمة لإظهار الأعلان بشكله النهائي إلى زيادة فاعلية دعم الرسالة الاتصالية كما في العينات (3، 2، 1، 1).

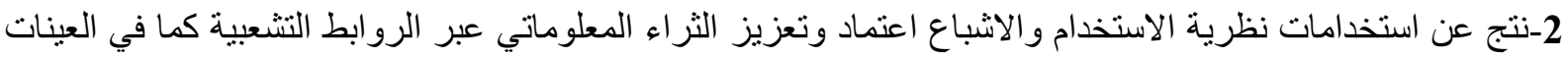

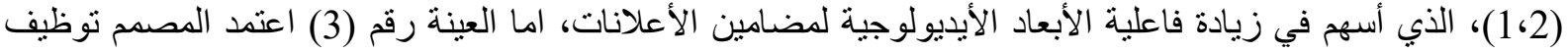

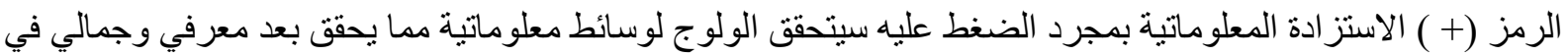

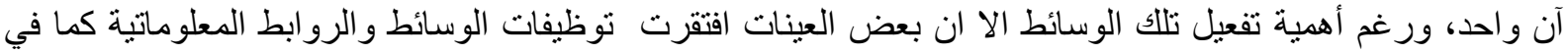

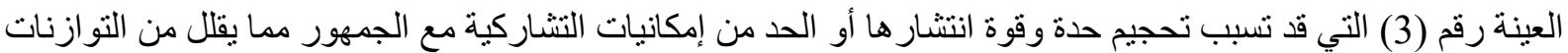

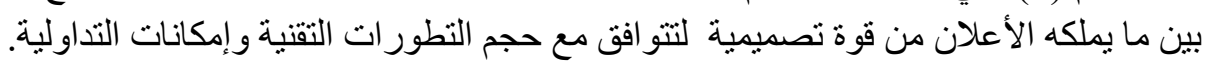

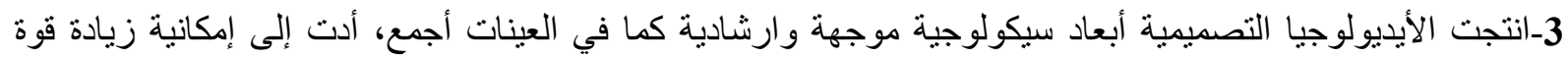

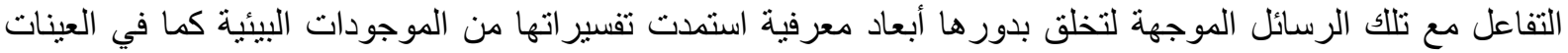

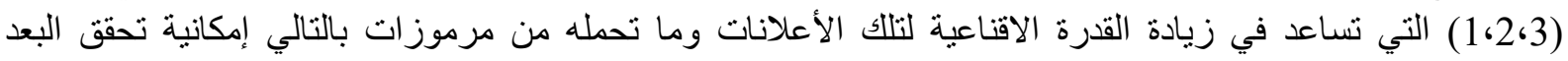

4-احتوت العينات (3،2،1، على نمط فكري وفق أيديولوجيا خاصة اعتمدها المصمم اظهرتها تنظيمات تصميمية فيها

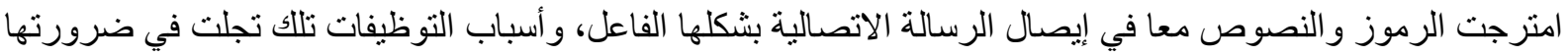

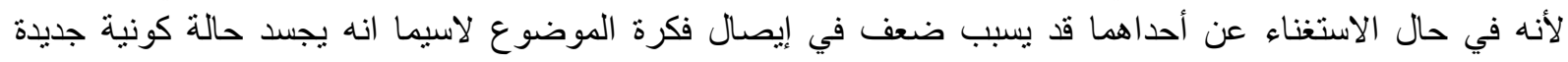

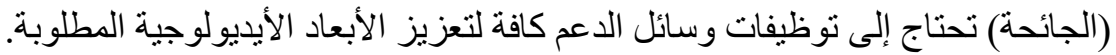

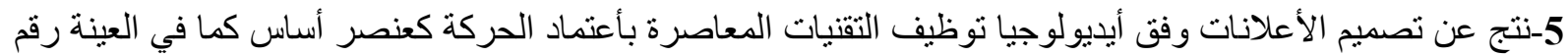

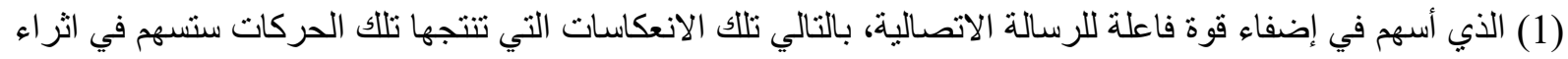
البعد الجمالي و المعرفي و السيكولوجي خارج نمطية العرض التلقيدي التي تميزت بها كل من العينات (3،2).

الاستنتاجات

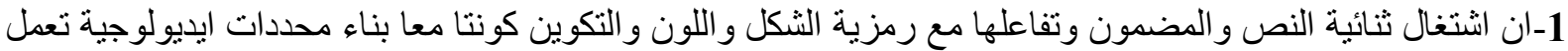

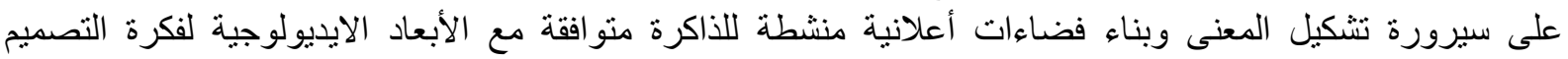
الأعلاني، مما سبب في زيادة فاعلية الرسالة الاتصالية. 2-ان الأبعاد الايديولوجية تتشكل وفق قصدية المصدم التي يظهرها في الثكل البنائي للأعلانات الرقمية، لتحقيق غايات منها تفعيل الخطاب الاتصالي. 3-ان اثتغالية الاساليب التصميمية في بنية الأعلانات ساهدت في إضقاء طاقة تعبيرية لها أبعاد ايديولوجية متنو عة أسهمت في إضفاء الواقعية وزيادة الحافز البصري التصري و الذهني.

4-ان اقتر انات بنية عناصر التصميم وفق رؤى ايديولوجية كانت سبيا في تفعيل العملية الاتصالية.

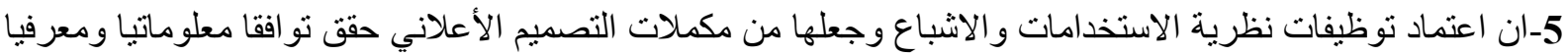

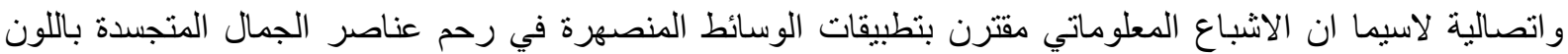

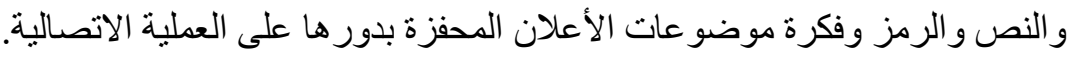

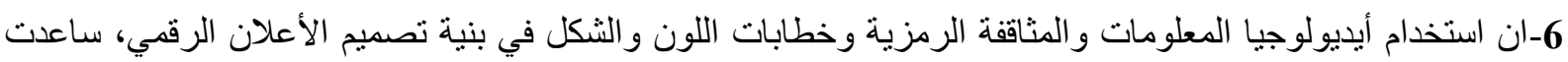

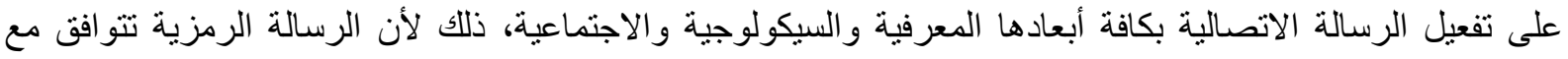

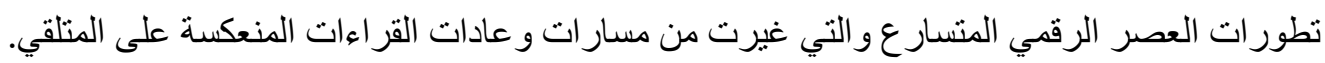

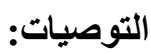
إيلاء تفعيل الجوانب الأيديولوجية وتوظيفاتها في تصاميم الأعلانات الرقمية ضمن تطبيقات مو اقع التواصل الاجتماعي.

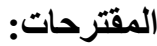
در اسة آلية توظيفات الوسائط المعلوماتية في تصاميم الأعلانات الرقمية. 
إريك ميغري (2018)، سوسيولوجيا الاتصال و الميديا، ط1، تر: نصر الدين العياضي، هيئة البحرين للثقافة والاثار، المنامة،مملكة البحرين.

بشير العلاق (2007)، علي محمد ربابعة، الترويج والأعلان التجاري،أسس، نظريات، نطبيقات،دخل متكامل، دار البازوري، عمان.

حسنين شفيق (2010)، الأعلام التفاعلي وما بعد التفاعلية، ط1، دار فكر وفن للطباعة و النشر و التوزيع، مصر .

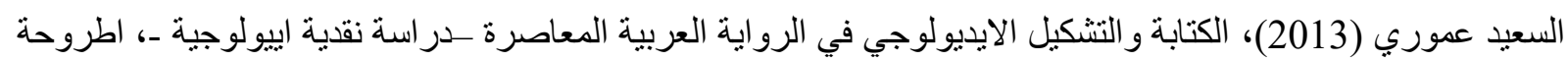

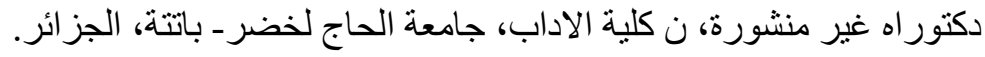

عبد الرزاق محمد الدليمي (2011)، الصحافة الالكترونبة والتكنلوجيا الرقمية، ط1، دار الثقافة للنشر و التوزيع، عمان. عبد الله العروي (2012)، مفهوم الايديولوجيا، ط8، المركز الثقافي العربي، الدار البيضاء، المغرب.

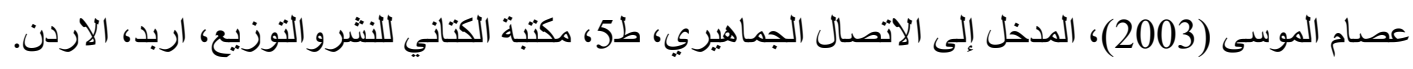
علي فلاح الزغبي (2010)، الاتصالات التسويقية ــدخل منهجي تطبيقي، ط1، دار المسيرة للنشر والتوزيع، عمان.

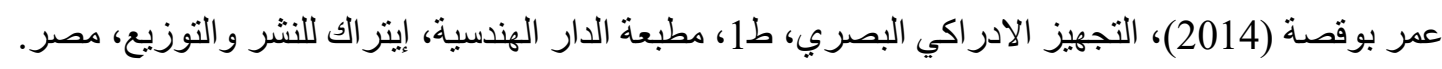

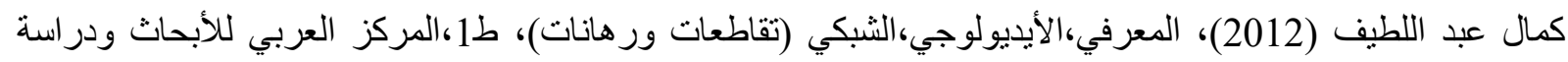
السياسات، بيروت.

محمد بن سعود البشر (2008)، أيديولوجيا الأعلام، ط1، دار عيناء للنشر، الرياض.

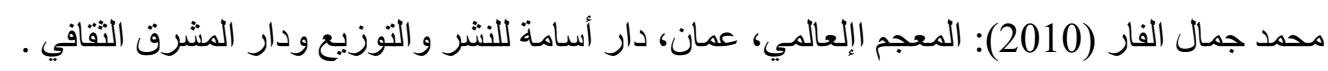
محمد خليل الرفاعي (2020)، فن التصوير الصحفي، منشور ات الجامعة الافتراضية السورية، سوريا.

محمد دقبري (1987)، ماهي الإبستمولوجيا، ط2، مطبعة المعارف الجديدة للنشر و التوزيع، الرباط.

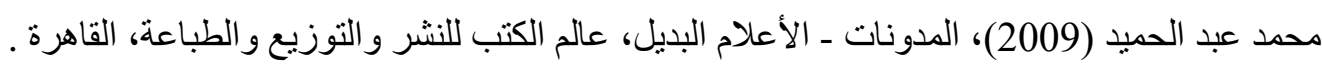
محمود الفظاظة (2012)، علاقة الأعلام الجديد بحرية الرأي والتغيير في فلسطين نموذجاً، المركز الفلسطيني للتنمية والحريات الأعلامية، ط1، الاعلة رام الله، فلسطين.

مصطفى صادق عباس (2008)، الأعلام الجديد ـ المفاهيم و الوسائل و التطبيقات،طين، دار الثروق للنشر و التوزيع، عمان. معتصم بابكر مصطفى (2014)، أيديولوجيا شبكات التواصل الاجتماعي وتشكيل الر أي العام ، الجزيرة للار اسات، مركز التنوير المعرفي. هند رستم (2008)، اساسيات معالجة الصورة الرقمية، دار الكتب و الوثائق الوطنية، بغداد. المجلات

اماني مجاهد (2010)، استخدام الثبكات الاجتماعية في تقديم خدمات مكتبية متطورة، مجلة دراسات المعلومات، العدد الثامن، الرياض، السعودية.

سمر هاني السعيد (2015)، تكنلوجيا الزجاج في تصميم الأعلان التفاعلي، مجلة التصميم الدولي،الجمعية العلمية

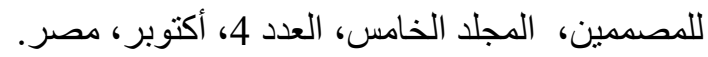

عبد الله عامر (2007)، الفيس بوك و عالم التكنلوجيا، مجلة العلوم و التكنلوجيا، عدد 14، جامعة البتراء، عمان.

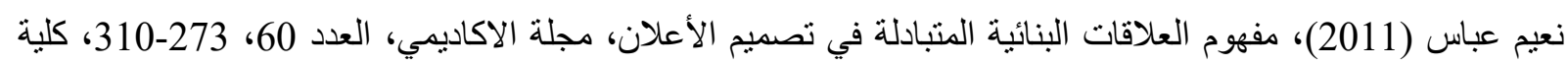
الفنون الجميلة، جامعة بغداد. 
Aarron Walter (2011), DESIGNING FOR EMOTION, Publisher: Jeffrey Zeldman, New York.

Erben,T.et al (2009), 'Teaching English Language Learners through Technology" , New yurok and london: Rutledge , on - line): http://www.educause.edu/EDUCAUSE+Rev...dayorNot/157925

Maggie Macnab (2012) , Design by Nature-Using Universal Forms and Principles in design-, Printed and bound in the United States of America.

Susan M.Weinschenk (2011) , 100 THINGS EVERY DESIGNER NEEDS TO KNOW ABOUT PEOPLE, Printed and bound in the United States of America.

William Lidwell, Jill Butler (2010) _ Universal Principles of Design , Foreword by Kimberly Elam, Printed in Singapore.

مصادر النت

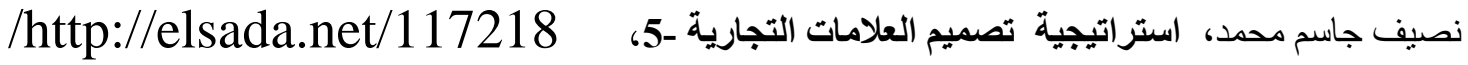

